University of South Florida

DIGITAL COMMONS

Digital Commons @ University of

@ UNIVERSITY OF SOUTH FLORIDA

South Florida

\title{
A Structural Equation Analysis of Family Accommodation in Pediatric Obsessive-Compulsive Disorder
}

Nicole Elise Caporino

University of South Florida, Nicole.Caporino@gmail.com

Follow this and additional works at: https://digitalcommons.usf.edu/etd

Part of the American Studies Commons, and the Clinical Psychology Commons

\section{Scholar Commons Citation}

Caporino, Nicole Elise, "A Structural Equation Analysis of Family Accommodation in Pediatric ObsessiveCompulsive Disorder" (2011). USF Tampa Graduate Theses and Dissertations.

https://digitalcommons.usf.edu/etd/3030

This Dissertation is brought to you for free and open access by the USF Graduate Theses and Dissertations at Digital Commons @ University of South Florida. It has been accepted for inclusion in USF Tampa Graduate Theses and Dissertations by an authorized administrator of Digital Commons @ University of South Florida. For more information, please contact digitalcommons@usf.edu. 
A Structural Equation Analysis of Family Accommodation in Pediatric ObsessiveCompulsive Disorder

by

Nicole Elise Caporino

A dissertation submitted in partial fulfillment

of the requirements for the degree of

Doctor of Philosophy

Department of Psychology

College of Arts and Sciences

University of South Florida

Co-Major Professor: Eric Storch, Ph.D.

Co-Major Professor: Vicky Phares, Ph.D.

Jason Beckstead, Ph.D.

Marc Karver, Ph.D.

Kevin Thompson, Ph.D.

Joseph Vandello, Ph.D.

Date of Approval:

June 10, 2010

Keywords: Obsessive-Compulsive Disorder, Children,

Treatment, Assessment, Family Accommodation

Copyright (@ 2011, Nicole Elise Caporino 


\section{Table of Contents}

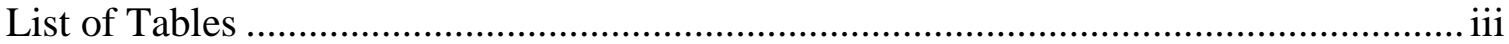

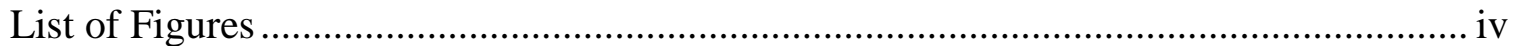

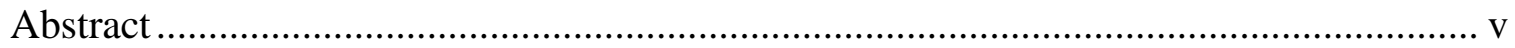

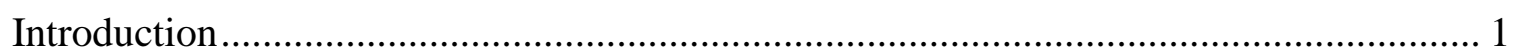

Cognitive-Behavioral Model of OCD ........................................................... 2

Treatment of Pediatric OCD .......................................................................... 3

Family Accommodation as a Predictor of Treatment Response............................... 4

CBT Modified to Target Predictors of Poor Response …….................................. 7

Correlates of Accommodation .......................................................................... 8

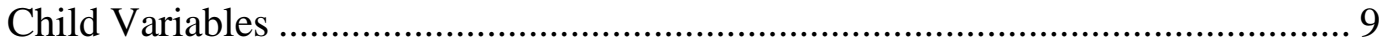

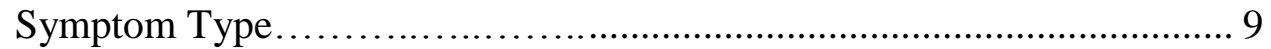

Obsessive-Compulsive Symptom Severity …………………................... 10

Functional Impairment ....................................................... 11

Internalizing Problems ...................................................................... 13

Externalizing Problems ...................................................................... 14

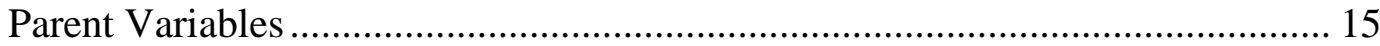

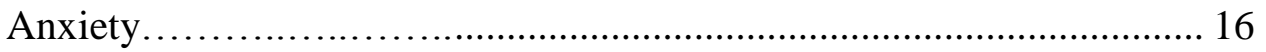

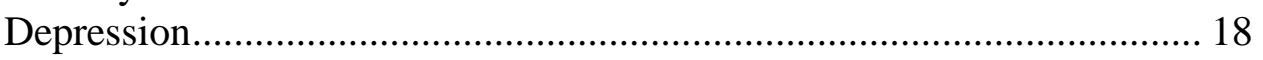

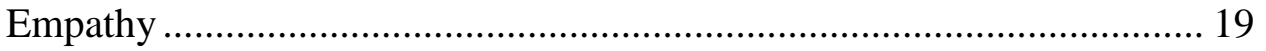

Consideration of Future Consequences ……………………………...... 21

Beliefs About Accommodation............................................................ 22

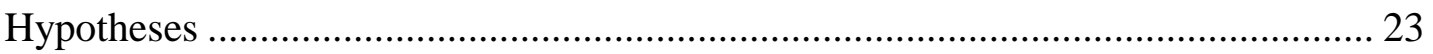

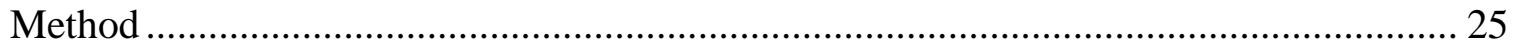

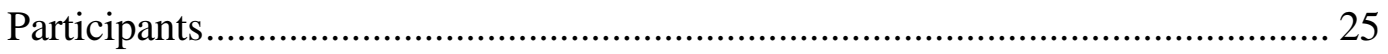

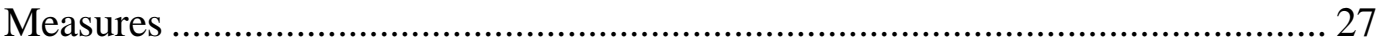

Background Questionnaire.................................................................... 27

Anxiety Disorders Interview Schedule for DSM-IV ............................... 27

Schedule for Affective Disorders and Schizophrenia for School Age

Children.................................................................................... 28

Children's Yale-Brown Obsessive Compulsive Scale …………………... 29

Child Obsessive-Compulsive Impact Scale-Revised................................. 30

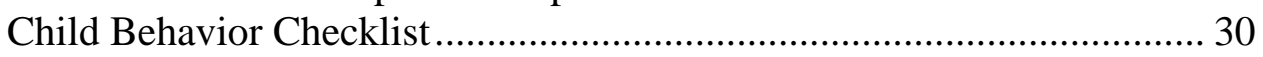

Brief Symptom Inventory ………………………………………..... 31

Interpersonal Reactivity Index …………………………..................... 32

Consideration of Future Consequences ……………………………........ 33

Family Accommodation Scale ............................................................... 34

Parent Beliefs Questionnaire.................................................................. 35

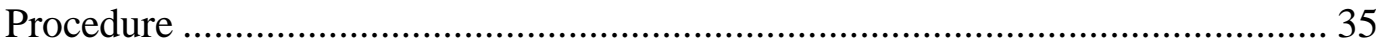

Recruitment of Participants..................................................................... 35 


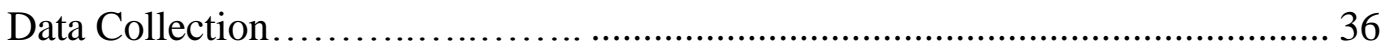

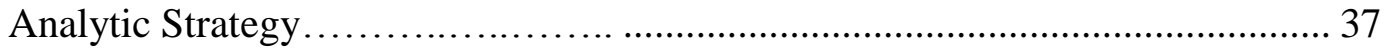

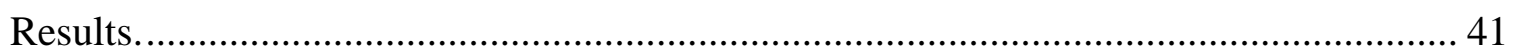

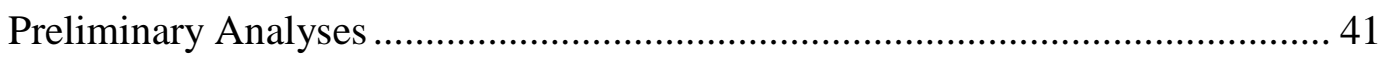

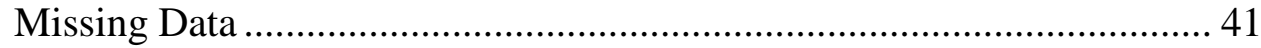

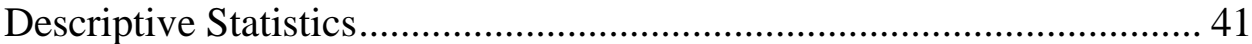

Model Fit............................................................................................... 41

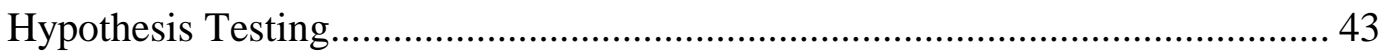

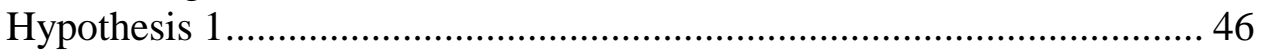

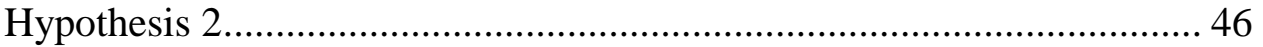

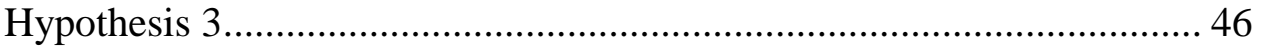

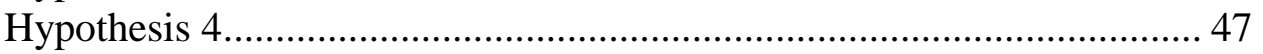

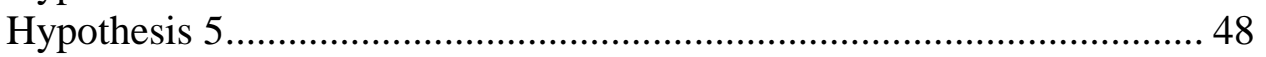

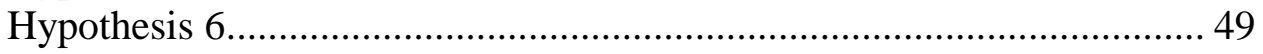

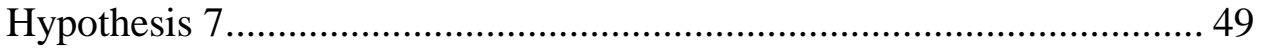

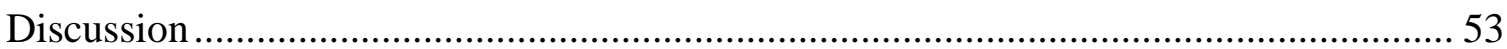

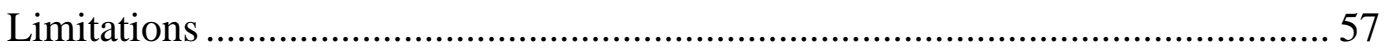

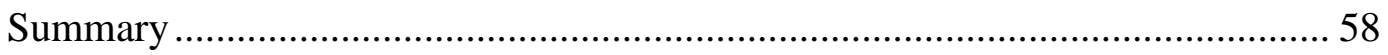

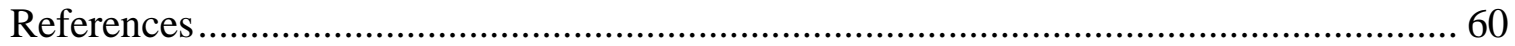




\section{List of Tables}

Table 1: Zero Order Correlations, Means, Standard Deviations, and Reliability Estimates for Indicators

Table 2: $\quad$ Summary of Model Fit Statistics ................................................................44

Table 3: Standardized Total Effects among Latent Variables in Final Model ..............46

Table 4: Frequencies with which Symptom Types were Exhibited and Accommodated Most Often

Table 5: Means and Standard Deviations for Parent Beliefs about

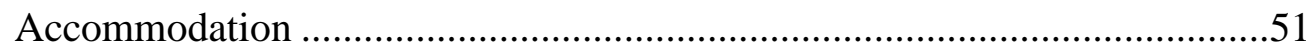

Table 6: Frequencies for Parent Beliefs about Accommodation .................................52

Table 7: Correlations among Parent Beliefs about Accommodation and Family Accommodation 


\section{List of Figures}

Figure 1: Model of child and parent variables related to family accommodation ............16

Figure 2: Final structural equation model ..........................................................

Figure 3: The interaction between parent empathy and consideration of future consequences in the prediction of family accommodation .........................49 


\begin{abstract}
Family accommodation of symptoms conflicts with the primary goals of cognitive-behavioral therapy for pediatric obsessive-compulsive disorder (OCD) and can be an obstacle to positive outcomes. This study examined a structural equation model of parent and child variables related to family accommodation using a sample of 65 parentchild dyads recruited from a university-based clinic. Additionally, parents' motivations for engaging in accommodation were explored. Results generally supported the hypothesized model. Family accommodation mediated the relationship between OCD symptom severity and parent-rated functional impairment, child internalizing problems mediated the relationship between parent anxiety and family accommodation, and parent empathy and consideration of future consequences interacted to predict accommodation. Child externalizing problems significantly influenced family accommodation but neither of these two variables was affected by parent depression. Excessive reassurance seeking and cleaning/washing compulsions were relatively likely to be accommodated. Implications for clinical practice and directions for future research are discussed.
\end{abstract}


Introduction

Obsessive-compulsive disorder (OCD) is characterized by recurrent obsessions (i.e., intrusive thoughts or images) and/or compulsions (i.e., ritualized behaviors or avoidance) that cause significant distress and impairment. Approximately $2 \%$ to $4 \%$ of children and adolescents have been affected by OCD (e.g., Rapoport et al., 2000; Zohar, 1999; Douglass, Moffitt, Dar, McGee, \& Silva, 1995). If left untreated, pediatric OCD runs a chronic course (Rufer, Grothusen, Mass, Peter, \& Hand, 2005) and is associated with significant impairment in multiple domains (Piacentini, Peris, Bergman, Chang, \& Jaffer, 2007; Piacentini, Bergman, Keller, \& McCracken, 2003).

Common themes of obsessions among children and adolescents include fears of contamination (e.g., dirt or germs); fears of harm to oneself or others; the need for symmetry, exactness, or order; excessive concern with religious or moral conduct (e.g., extreme fear of committing a sin); preoccupation with lucky or unlucky numbers; and concerns with forbidden sexual or aggressive thoughts (e.g., Masi et al., 2005; Swedo, Rapoport, Leonard, Lenane, \& Cheslow, 1989). Common compulsions include cleaning or decontamination rituals (e.g., excessive washing); checking (e.g., locks, appliances, homework), counting, and repeating (e.g., words or phrases); confessing, praying, and reassurance seeking; touching, tapping, and rubbing; behaviors intended to prevent harm; and hoarding. Certain compulsions (e.g., washing) are often linked to specific obsessive themes (e.g., contamination) and it is common for the symptom constellation to change 
throughout childhood and adolescence (Rettew, Swedo, Leonard, Lenane, \& Rapoport, 1992).

\section{Cognitive-Behavioral Model of OCD}

One of the most widely accepted etiological accounts of OCD is the cognitivebehavioral model (Rachman, 1997, 1998; Salkovskis, 1985, 1989). It is derived from well-established learning principles (e.g., operant conditioning) and has considerable support from empirical studies of adults (e.g., Abramowitz, Tolin, \& Street, 2001; OCCWG, 2003) and children (e.g., Reynolds \& Reeves, 2008). The basis of this model is that individuals with OCD appraise normally occurring intrusive thoughts (e.g., thoughts about harming a parent) as highly meaningful or personally significant (e.g., “This means that I'm a terrible child") whereas most people would dismiss them as "mental noise." Interpretations of the unwanted thoughts as posing a threat for which the individual is personally responsible result in distress, causing him/her to become preoccupied with controlling the unwanted thoughts (thought suppression). Consequently, these thoughts escalate into persistent clinical obsessions and lead the individual to engage in compulsive rituals and avoidance behavior in an effort to remove the intrusive thoughts and to prevent feared consequences. These strategies to reduce anxiety are effective in the short term and are thus, negatively reinforced. However, they are maladaptive in the long term because they prevent habituation that typically occurs when individuals are exposed to anxiety-producing stimuli for longer periods of time and they serve as reminders of the intrusive thoughts, triggering their reoccurrence. Also, compulsions maintain dysfunctional beliefs and misinterpretations of intrusive thoughts because the individual attributes the nonoccurrence of the feared consequences to having 
performed the ritual (rather than to the reality that the feared consequence is unlikely to occur).

\section{Treatment of Pediatric OCD}

Treatments derived from the cognitive-behavioral model are considered frontline interventions for youth with OCD, according to expert consensus guidelines (March, Frances, Kahn, \& Carpenter, 1997) and practice parameters (American Academy of Child and Adolescent Psychiatry, 1998). Specifically, cognitive-behavioral therapy (CBT) with exposure and response prevention (E/RP), delivered alone or in conjunction with a serotonin reuptake inhibitor (SRI), meets the requirements for a probably efficacious treatment (Chambless \& Hollon, 1998; Chambless et al., 1998; Chambless et al., 1996) based on the results of a randomized controlled trial (Pediatric OCD Treatment Study Team, 2004). Exposure and response prevention involves collaborating with the client to develop a fear hierarchy based on ratings of distress associated with anxiety-provoking stimuli and progressively exposing the client to these stimuli while preventing him/her from engaging in compulsions. Although anxiety levels increase initially, prolonged exposure (either in vivo or imaginal) results in habituation and allows clients to learn that previous cognitions regarding danger and responsibility are inaccurate (March, Franklin, Nelson, \& Foa, 2001; Foa \& Kozak, 1986). Clients are typically assigned daily homework assignments that involve exposure to stimuli similar to those targeted in session and tangible reinforcers may be provided for children who do not understand that enduring the exposures will provide long-term relief from anxiety. The cognitive component of CBT involves teaching the client to identify and challenge dysfunctional thoughts (e.g., inflated responsibility; overestimation of risk) that motivate compulsions 
using self-talk, cognitive restructuring, and behavioral experiments to test the validity of distorted cognitions.

Although CBT is considered to produce the most favorable response among treatments for pediatric OCD, as many as $35 \%$ of clients demonstrate little or no improvement (Pediatric OCD Treatment Study Team, 2004; Piacentini, Bergman, Jacobs, McCracken, \& Kretchman, 2002; Benazon, Ager, \& Rosenberg, 2002). Further, clients who are classified as treatment responders often have residual symptoms. According to a review by de Haan (2005), between $50 \%$ and $75 \%$ of children and adolescents with OCD remain symptomatic after completing a full course of treatment.

\section{Family Accommodation as a Predictor of Treatment Response}

Given that many clients do not respond optimally to cognitive-behavioral therapy, increasing attention has been paid to identifying variables that predict treatment response. Variables that have consistently emerged as predictors thus far include symptom severity, symptom subtype, severe depression, therapeutic alliance, and family dysfunction (see Keeley, Storch, Merlo, \& Geffken, 2008 for a review).

In addition to general family dysfunction (which may involve parental hostility, criticism, and rejection), there is mounting evidence that family accommodation predicts treatment response (e.g., Merlo, Lehmkuhl, Geffken, and Storch, 2009). Family accommodation refers to actions taken by family members to facilitate rituals (e.g., by providing necessary objects), yield to the child's demands (e.g., by following a certain routine in order to minimize anxiety), provide reassurance to the child (e.g., by answering questions repeatedly), assist with or complete tasks (e.g., homework, chores) for the child, or decrease the child's responsibility (e.g., by limiting attempts at discipline) 
because symptoms of OCD interfere with his/her ability to meet expectations (Storch et al., 2007a). Farrell and Barrett (2007) have distinguished between direct accommodation, which occurs when family members become involved in a child's symptoms, and indirect accommodation, which occurs when family members make subtle changes to their own routines with the purpose of avoiding a "moment" related to the child's OCD. Examples of direct accommodation include physically helping a child to wash or clean, opening doors or turning on light switches for the child, and answering excessive questions. Examples of indirect accommodation include ensuring that the television is not turned on during times at which the child might hear news stories related to his/her obsessions, not touching the child's personal belongings in order to avoid contamination, and not entering the child's room in order to avoid changing the exact positions of his/her belongings (Farrell \& Barrett, 2007).

Family accommodation of obsessive-compulsive symptoms is extremely common. Renshaw, Sketekee, and Chambless (2005) reported that across 13 studies of adults and children with OCD conducted between 1983 and 2003, rates of accommodation of symptoms ranged from $62 \%$ to $100 \%$ and rates of actual participation in rituals ranged from 39\% to 75\%. Further, Calvocoressi et al. (1995) reported that participation in rituals occurred on a daily basis for $25 \%$ of relatives and Shafran, Ralph and Tellis (1995) indicated that only $2 \%$ of relatives had never acquiesced to clients' requests to participate in rituals. Rates of accommodation by parents of youth with OCD appear to be even higher than rates of accommodation by family members of adults with the disorder. Many children with OCD are secretive about their rituals and "save" them for home rather than engaging in them before peers, teachers, or strangers (King, 
Ollendick, \& Montgomery, 2005), which likely increases the extent to which the rituals interfere with family routines and consequently, adds to the pressure experienced by parents to accommodate these rituals. In a recent study by Peris et al. (2008), more than half of the parents sampled reported some form of accommodation on a daily basis. The most common manifestations of accommodation were verbal reassurance about unsubstantiated obsessions or fears, facilitation of avoidance, and actual participation in rituals. These results were consistent with Storch et al. (2007a), who also sampled parents exclusively.

Family accommodation is thought to reinforce OCD-related rituals and avoidance. As Storch et al. (2007a) pointed out, family accommodation conflicts with the primary goals of cognitive-behavioral therapy because it prevents the child from habituating to the anxiety that is experienced when he/she refrains from engaging in rituals and limits the child's opportunities to learn that feared consequences are not likely to occur. Also, accommodating a child's symptoms diminishes the aversive consequences of obsessivecompulsive behavior (e.g., interference with preferred activities), reducing motivation for change.

Several studies in the adult literature have supported the claim that family accommodation hinders treatment response. In a sample consisting primarily of adults, Amir, Freshman, and Foa (2000) found that family accommodation at baseline predicted decrease in obsessive-compulsive symptoms following behavior therapy, even when the effects of pretreatment symptom severity scores were controlled. Ferrao et al. (2006) conducted a case-control study to identify differences between adults with treatmentrefractory OCD and adults who responded to conventional treatment approaches and 
found that the former had significantly higher scores on a clinician-rated measure of family accommodation. Steketee (1993) reported that a decrease in family members' tendencies to provide assistance with rituals or avoidance behaviors was associated with better outcomes of intensive behavior therapy at nine months post-treatment.

A recent study in the pediatric literature provides additional evidence that family accommodation can be an obstacle to positive outcomes of cognitive-behavioral therapy for OCD. Merlo et al. (2009) sampled 50 youth and their parents, and found that change in levels of family accommodation from baseline to post-treatment was significantly associated with parent- and clinician-rated symptom severity post-treatment, even when controlling for pre-treatment symptom severity. Further, parents of youth who responded to treatment demonstrated significantly greater reductions in accommodation than parents of non-responders.

\section{CBT Modified to Target Predictors of Poor Response}

Given the high rates of accommodation by family members of youth with OCD, treatments have been modified to target this predictor of poor outcome. Cognitivebehavioral family-based therapy (CBFT; Barrett, Healy-Farrell, \& March, 2004), for example, is a modification of standard CBT that involves extensive family participation and specific attention to accommodation. In a randomized controlled trial, CBFT yielded greater symptom reductions and higher remission rates than those that have been reported for treatments with less well-developed family components (e.g., Pediatric OCD Treatment Study [POTS], 2004). Further, treatment gains were maintained 18 months post-treatment for the majority of participants (Barrett, Farrell, Dadds, \& Boutler, 2005). In CBFT, family accommodation is addressed through psychoeducation in which 
accommodating behaviors are externalized as a symptom of OCD. The child and his/her family collaborate to monitor accommodating behaviors and the child increasingly gives permission to his/her parents to withdraw accommodation and/or reassurance, in small steps that are established by constructing a hierarchy in a manner similar to developing a hierarchy for exposure (Farrell \& Barrett, 2007).

Storch et al. (2007b) modified the protocol used in POTS (2004) to require that at least one parent attend all CBT sessions with the client. This "family-based" format was utilized to facilitate understanding of treatment principles, encourage optimal effort from the child during exposures, promote generalization of gains made in session by recruiting the parent to serve as a "coach" at home, and reduce parental accommodation of symptoms. Family-based CBT delivered on a weekly basis was compared to an intensive approach, which involved daily sessions. At post-treatment, remission rates in the weekly and intensive groups were $50 \%$ and $75 \%$, respectively. There were greater reductions in family accommodation in the intensive condition than in the standard CBT condition, presumably because daily sessions permit closer monitoring and more frequent feedback to families about their accommodating behavior (Storch et al., 2007b).

\section{Correlates of Accommodation}

In addition to evaluating the relative efficacy of different formats for delivering extant family-based interventions, continued research on accommodation is necessary so that treatment response can be maximized by more effectively tailoring the content of interventions to families. Several studies in the adult literature have examined correlates of family accommodation (e.g., Stewart et al, 2008a; Amir, Freshman, \& Foa, 1995; 
Cooper, 1996). To date, only two such studies have been published in the pediatric literature (Storch et al., 2007a; Peris et al., 2008).

\section{Child Variables}

Storch et al. (2007a) and Peris et al. (2008) have investigated the relationship between family accommodation and various child variables, including obsessivecompulsive symptom severity, functional impairment, internalizing problems, and externalizing problems. These variables in addition to symptom type, which has not yet been studied in relation to accommodation of children's symptoms, are discussed below.

Symptom type. Despite core psychopathology that involves engaging in compulsions to alleviate anxiety associated with obsessions, there is significant heterogeneity among clients with OCD in terms of clinical presentation. Factor analyses of the Children's Yale-Brown Obsessive Compulsive Scale Symptom Checklist (CYBOCS; Scahill et al., 1997) and its counterpart adult measure (Y-BOCS; Goodman et al., 1989) have generally identified four major symptom dimensions: contamination obsessions and cleaning compulsions, sexual/religious/aggressive obsessions and checking compulsions, symmetry obsessions and ordering/counting/repeating compulsions, and hoarding obsessions and compulsions (e.g., Stewart et al., 2008b; Mataix-Cols, Nakatani, Micali, \& Heyman, 2008; Bloch, Landeros-Weisenberger, Rosario, Pittenger, \& Leckman, 2008; Stewart et al., 2007; McKay et al., 2004).

It is possible that the frequency with which parents accommodate children's obsessive-compulsive symptoms depends on the dimension along which the symptoms fall. Accommodating some types of compulsions (e.g., reassurance seeking related to violent obsessions) might require less response effort and cause less disruption to family 
routine/lifestyle than accommodating others (e.g., hoarding). Clinical experience suggests that parents are relatively intolerant of hoarding symptoms, in particular (Storch et al., 2007c). However, contamination obsessions or cleaning compulsions, in adults at least, appear likely to be accommodated (Stewart et al., 2008a). To date, there have not been any published studies in the pediatric literature that have examined the relationship between family accommodation and symptom type.

Obsessive-compulsive symptom severity. Symptom severity refers to the frequency with which obsessions and/or compulsions occur, the level of associated distress and interference with daily functioning, the extent to which efforts are made to resist symptoms, and the degree to which symptoms are experienced as controllable. It has been observed clinically that parents engage in accommodating behaviors with the intention of reducing the child's distress as well as the time that he/she spends engaging in rituals (Storch et al., 2007a). However, because accommodation serves to reinforce the child's rituals and avoidance behavior, the parents' efforts are ultimately unsuccessful and the severity of symptoms does not decrease. Thus, one might expect there to exist a relationship between symptom severity and parental accommodation.

A few recent studies have evaluated this possibility. Storch et al. (2007a) found that total scores on the Family Accommodation Scale (FAS; Calvocoressi et al., 1995) were significantly and positively associated with symptom severity in a sample of youth ranging in age from 7 to 17 years. This finding was replicated by Merlo et al. (2009). Peris et al. (2008) reported a significant relationship between obsessive-compulsive symptom severity and scores derived from a subset items from the FAS that assess behavioral involvement in symptoms but not total scores (which are also based on items 
that assess the perceived consequences of not accommodating). Among the limitations common across these studies is the use of regression-based techniques, which do not account for error in questionnaire-type measurement.

Functional impairment. For OCD to be diagnosed according to DSM-IV criteria, a youth's symptoms must cause marked distress, consume an hour or more each day, or result in significant impairment; that is, interfere with daily routines, academic performance, or social activities or relationships. Piacentini et al. (2003) conducted a study of impairment in a sample of 151 youth with a primary diagnosis of OCD and reported that the large majority of the sample $(88 \%$ by parent report and $85 \%$ by child report) exhibited a significant problem in at least one functional domain: school/academic (e.g., getting to school on time, doing homework), home/family (e.g., getting ready for bed at night, getting along with siblings), and social (e.g., going to a friend's house during the day, spending the night at a friend's house). Nearly half of the sample ( $46 \%$ by parent report and $44 \%$ by child report) reported at least one significant problem in each of the three domains. Similar findings have been reported in subsequent studies (e.g., Valderhaug \& Ivarsson, 2005).

It appears that parents accommodate obsessive-compulsive symptoms not only to reduce children's distress but also to try to minimize OCD-related impairment (Storch et al., 2007a). For example, parents might schedule their morning around allowing the child with OCD enough time in the bathroom to complete excessive grooming rituals in order to make sure that he/she gets to school on time. However, accommodation often leads to greater impairment by limiting children's opportunities to develop problem solving skills in addition to putting a strain on relationships with family members (e.g., Steketee \& Van 
Noppen, 2003). For example, conflict may ensue because parents experience stress due to added responsibility for the child's functioning and siblings are inconvenienced by the parents' accommodating behaviors, if not also engaging in accommodation themselves. Using data collected from 57 parent-child dyads, Storch et al. (2007a) found a significant positive association between family accommodation and parent reports of child impairment in each of three domains of functioning: home/family, school/academic, and social. As expected, the association between accommodation and impairment in child functioning at home was most pronounced. The relationship between family accommodation and child-reported impairment, however, was not significant. These findings were replicated by Merlo et al. (2009); family accommodation was significantly correlated with parent-rated but not child-rated impairment prior to the start of family-based cognitive-behavioral therapy. It has been suggested that children are more likely than parents to view symptoms as minimally impairing, either because children experience their symptoms as ego-syntonic (Geffken et al., 2005) or because they do not have the opportunity to observe decreases in functioning to the extent that their families are engaging in accommodation (Storch et al., 2007a).

Storch et al. (2007a) also reported that family accommodation mediated the relation between obsessive-compulsive symptom severity and parent-reported childimpairment. The possibility that symptom severity influences the extent of family accommodation, which in turn contributes to the level of functional impairment in children, underscores the importance of addressing accommodation using family-based treatment approaches. However, no attempt has been made to replicate the finding. 
Internalizing problems. Internalizing problems involve feelings or states that are commonly viewed as inner-directed (as opposed to directed at others); they include anxiety, depression, somatic complaints without known medical cause, and withdrawal from social contacts (Achenbach \& Rescorla, 2001; Reynolds, 1992). As many as 40 to 60 percent of children with OCD have another anxiety disorder (Storch et al., 2008a; Geller et al., 2001; Zohar, 1999), the most common of which is generalized anxiety disorder (e.g., Storch et al., 2008a). Depression is also common among children and adolescents with OCD (e.g., Douglass et al., 1995; Peterson, Pine, Cohen, \& Brook, 2001), with comorbidity rates of Major Depressive Disorder in clinical samples ranging from $10 \%$ to $73 \%$ (Geller, Biederman, Griffin, Jones, \& Lefkowitz, 1996; Geller et al., 2001, 2003; Hanna, 1995; Riddle et al., 1990; Swedo et al., 1989). Further, comorbidity studies using dimensional measures have documented high rates of problematic internalizing symptoms that do not meet the threshold for clinical diagnosis (e.g., Ivarsson, Melin, \& Wallin, 2008).

It has been observed that children often display increasing anxiety and distress when parents try to refrain from accommodating obsessive-compulsive symptoms (Storch et al., 2007a). Thus, it seems likely that the level of internalizing problems exhibited by children is related to extent to which their parents engage in accommodation. However, studies that have examined this relationship yielded mixed findings. Although Storch et al. (2007a) reported a significant, positive association between total scores on the FAS and the Internalizing Problems scale of the Child Behavior Checklist (CBCL; Achenbach \& Rescorla, 2001), this finding was not replicated by Peris et al. (2008). Additional research to clarify the relationship between 
child internalizing problems and family accommodation would assist in determining the benefit of incorporating treatment components that directly address general anxiety, for example (as opposed to just eliminating specific fears through exposure).

Externalizing problems. Externalizing problems involve conflict with other people and with their expectations for children's behavior (Achenbach \& Rescorla, 2001). They include disruptive behaviors (e.g., inattention, hyperactivity, aggression, defiance) and risk-taking (e.g., sexual behaviors drug and alcohol use). Studies have documented high rates of disruptive behavior disorders (i.e. oppositional defiant disorder, conduct disorder, disruptive behavior disorder not otherwise specified; 10-53\%) and attention-deficit/hyperactivity disorder (ADHD; 10-50\%) in samples of children with OCD (e.g., Storch et al., 2008b; Geller et al., 1996, 2001, 2003; Hanna, 1995). At least one study that used a dimensional measure of externalizing symptoms revealed high rates of problematic aggressive behavior among children with OCD (as compared to normative data from the general population), even when diagnostic criteria were not met (Ivarsson, Melin, \& Wallin, 2008).

It is possible that families accommodate obsessive-compulsive symptoms even if they believe that accommodation is not helpful in order to avoid negative interpersonal consequences of refraining from accommodation (e.g., expressions of anger from the suffering individual). According to Cooper (1996), outbursts or tantrums are common among adolescents with OCD, particularly when symptoms are not accommodated, and cause many parents to "walk on eggshells." In a study conducted by Storch et al. (2007a), $16 \%$ of parents indicated that child displays of anger in response to parent refusal of accommodation occurred nearly every day. Also, total scores on the parent-report 
version of the FAS were significantly and positively associated with scores on the Externalizing Problems scale of the CBCL. Although Peris et al. (2008) failed to replicate this finding, they reported that externalizing problem scores were significantly associated with more frequent modification of family routines and with worse child consequences of non-accommodation (each measured using three items from the FAS).

The possibility that family accommodation is more likely when the child with OCD also exhibits externalizing problems is consistent with research showing that the presence of a comorbid disruptive behavior disorder or ADHD has a negative impact on treatment response (Storch et al., 2008b). Additional evidence of a relationship between family accommodation and externalizing problems would provide more support for the suggestion that the treatment of pediatric OCD could be enhanced by incorporating empirically supported behavior management strategies (Storch et al., 2007a; Peris et al., 2008).

\section{Parent Variables}

Clinical observations have suggested that targeting family accommodation can lead to decreases in symptom severity and functional impairment, even if the child client is unwilling to fully participate in treatment (Merlo et al., 2009). Thus, identifying parent variables associated with accommodation could lead to parent-focused interventions that would not only improve outcomes for youth but might also increase rates of service utilization. Aside from the study by Peris et al. (2008), which included assessments of parents' obsessive-compulsive symptoms, anxiety, hostility, and global psychopathology, there has not been any research conducted to investigate parent-level correlates of accommodation. In addition to mental health problems, such as anxiety and depression, 
it is possible that traits such as empathy and tendency to focus on the present could contribute to difficulty refraining from accommodation. These variables are considered below. A theoretical model of their relationships to child-level variables and accommodation of obsessive-compulsive symptoms is presented in Figure 1.

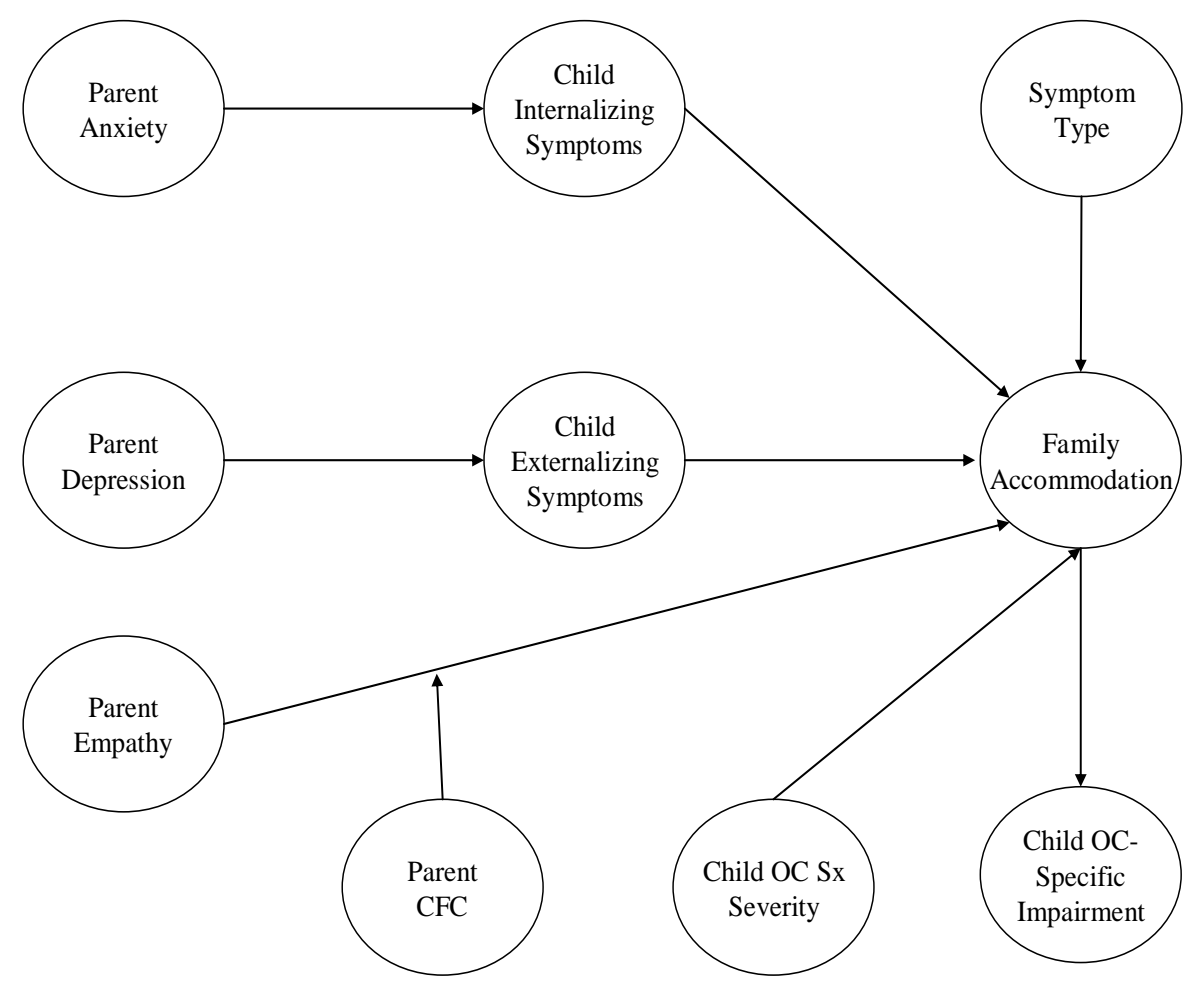

Figure 1. Model of child and parent variables related to family accommodation.

Anxiety. Anxiety disorders are relatively common among relatives of individuals diagnosed with obsessive-compulsive disorder (e.g., Carter, Pollock, Suvak, \& Pauls, 2004; Nestadt et al., 2001; Black, Noyes, Goldstein, \& Blum, 1995). These disorders all involve fear surrounding specific stimuli or situations that is maintained by distorted perceptions of danger and related avoidance or "safety-seeking" behavior (see reviews by Storch, Abramowitz, \& Goodman, 2008; Barlow, 2002). 
Parents who experience anxiety might be especially inclined to engage in accommodation for several reasons. First, they might share their children's fears (e.g., of contamination) or at least relate to the distress that their children experience upon being exposed to fear-provoking stimuli/situations, increasing their motivation to "rescue" their children. Second, anxious parents might fear escalating expressions of distress from their child (e.g., panic-like symptoms), especially if they experience their own arousal-related body sensations as scary. Similarly, anxious parents might be more likely than nonanxious parents to fear that their children will be angry and ultimately resent them if they don't "help" by engaging in accommodation. Third, given that anxious parents struggle to manage their own symptoms, they are more likely than non-anxious parents to lack the energy or resources to actively cope with their children's expressions of distress. Finally, anxious parents have a learning history that involves repeated reinforcement of the use of avoidance strategies, which could be expected to generalize to novel anxiety-producing situations involving their children. Accommodating their children's obsessivecompulsive symptoms is a way to avoid or escape any anxiety that they may experience when their children are distressed or confronted with situations that the parents also fear.

Previous studies have provided preliminary support for the idea that parental anxiety predicts accommodation. Peris et al. (2008) found that parents' scores on the Anxiety subscale of the Brief Symptom Inventory (Derogatis, 1993; Derogatis \& Melisaratos, 1983) were positively associated with behavioral involvement in their children's obsessive-compulsive symptoms (measured using a subset of items from the FAS). Amir, Freshman, and Foa (2000) sampled relatives (e.g., parents, siblings, spouses) of adolescents and adults with OCD and reported a significant, positive 
correlation between scores on the State-Trait Anxiety Inventory (Spielberger, Gorsuch, Lushene, \& Jacobs, 1983) and total scores on the FAS. To date, there have not been any published studies that have evaluated the possibility that the relationship between parental anxiety and accommodation could be explained, in part, by the presence and severity of child internalizing problems.

Depression. There is some evidence that depression occurs at higher rates in families of individuals with obsessive-compulsive disorder as compared to the general population (e.g., Nestadt et al., 2001; Hudson et al., 2003). Depression is characterized by feelings of sadness and/or diminished interest or pleasure in almost all activities. Other symptoms include fatigue, feelings of guilt or worthlessness, diminished ability to concentrate, significant changes in weight/appetite, sleep disturbances, psychomotor agitation or retardation, and recurrent thoughts of death (Diagnostic and Statistical Manual of Mental Disorders-Fourth Edition-Text Revision, 2000). Cognitive models of depression (e.g., Abramson, Metalsky, \& Alloy, 1989; Seligman, 1975; Beck, Rush, Shaw, \& Emery, 1979) emphasize that depressed individuals tend to have negative perceptions of the self and pessimistic expectations about the future. Consistent with these theories is research demonstrating that depressed parents are less likely than nondepressed parents to expect that they will be competent and effective in their parenting roles (e.g., Teti \& Gelfand, 1991; Bor \& Sanders, 2004; Haslam, Pakenham, \& Smith, 2006). Further, depression appears to affect parents' ability to be firm and consistent in their discipline of children and to avoid "giving in" to tantrums (e.g., Lovejoy, Graczyk, O'Hare, \& Neuman, 2000; Cunningham, Benness, \& Siegel, 1988). 
Depressed parents might experience decreased motivation to refrain from accommodation because they expect that efforts to resist their child's OCD-related demands will be unsuccessful. These expectations could be accurate, particularly for parents of children who exhibit externalizing problems. The loss of energy that accompanies depression might make it especially difficult for parents to respond effectively to defiant and/or aggressive behavior from their children. Also, these responses from children might be experienced as more burdensome to depressed parents than non-depressed parents given their affective vulnerability.

At least one study of adults with OCD found that relatives' depression was associated with accommodation (Amir, Freshman, \& Foa, 2000). However, it was not established that depression precedes accommodation; it is also possible the burden of accommodating obsessive-compulsive symptoms (e.g., by altering routines) leads to depression. Although a study in the pediatric literature reported that parents' global psychopathology was related to accommodation (Peris et al., 2008), there have not been any published studies that have looked specifically at parental depression.

Empathy. Empathy involves a sense of knowing or inferring the experience of another person (Goubert et al., 2005). Hoffman (2000) defines empathy as any process whereby the attended perception of another person's state generates a state that is more applicable to the other person's state or situation than to one's own prior state or situation. Some theorists have distinguished between cognitive and affective components of empathy (e.g. Davis, 1983; Miller \& Eisenberg, 1988). Cognitive empathy involves the ability to understand another person's perspective; that is, to comprehend another person's situation and take his/her psychological point of view (Davis, 1983). Affective 
empathy involves a visceral, emotional reaction that is congruent with the perceived welfare of another person (Batson \& Coke, 1981; Davis, 1983). Empathy has been recognized as an evolved function that allows for vicarious learning about dangers and for prosocial behavior (Preston \& de Waal, 2002; Williams, 2002) and may generate responses aimed at reducing personal distress (i.e., self-oriented responses) or responses that involve an altruistic motivation to help another person (i.e., other-oriented responses; Batson, 1991).

To date, there have not been any published studies that have investigated the relationship between dispositional empathy and parent accommodation of obsessivecompulsive symptoms in children and adolescents. Parents with relatively high levels of trait empathy might be especially likely to engage in accommodation because they have a strong emotional reaction to the anxiety that their children exhibit upon experiencing intrusive thoughts (affective empathy) and because they are able to recognize the feared consequences of not engaging in a ritual (cognitive empathy). Accommodating behaviors could be conceptualized as other-oriented responses intended to reduce the child's distress and improve his/her functioning. However, they might also represent selforiented responses intended to alleviate the parent's personal distress. Calvocoressi et al. (1999) found that $66 \%$ of parents believed that accommodation did not alleviate the client's distress and 50\% believed that it did not improve functioning. These findings support the possibility that for some families, at least, witnessing a relative in distress might be so aversive that they feel compelled to make some effort to alleviate that distress regardless of whether or not they appraise their efforts as effective. In these cases, accommodating behaviors might be negatively reinforced by distraction or escape, 
however temporary, from the emotional response that accompanies witnessing a family member's suffering.

Consideration of future consequences. According to Preston and de Waal (2002), empathic responses can be inhibited. The extent to which empathy motivates accommodation is likely to be affected by whether or not parents consider the long-term consequences of accommodating their children's symptoms at the same time that they attend to their children's distress. Many parents recognize that family accommodation exacerbates symptoms in the long run but feel pressured to utilize a short-term "fix" (Merlo et al., 2009). Whether or not parents submit to such pressure might be determined, in part at least, by individual differences at the trait level.

Consideration of future consequences (CFC; Strathman, Gleicher, Boninger, \& Edwards, 1994) is a construct that has been proposed to represent a relatively stable cognitive mindset that influences decisions about how to behave when there is a conflict between immediate and long-term outcomes. It refers to the extent to which individuals consider the potential distant outcomes of their current behaviors and are influenced by these potential outcomes. Individuals with high levels of CFC are willing to sacrifice immediate benefits (e.g., pleasure or convenience) in order to achieve more desirable future states whereas individuals with low levels of CFC place a high priority on immediate benefits at the expense of benefits that will not occur for some time.

Consideration of future consequences has been found to be negatively associated with impulsive sensation seeking (Joireman, Anderson, \& Strathman, 2003) and positively associated with academic achievements and goal attainment in college students. Individual differences in CFC affect decision making about preventive health 
behaviors (e.g., wearing sunscreen) and have important consequences for the persuasiveness of communications about such behavior (Orbell \& Kyriakaki, 2008). A broader but related construct, future time perspective, has been found to predict the success of a brief motivational interviewing intervention delivered to heavy drinking college students (Carey, Henson, Carey, \& Maisto, 2007). Contrary to hypotheses, students with low scores on a measure of future time perspective benefited more from motivational interviewing than students with high scores, perhaps because they had more to gain from the intervention.

Considering CFC in the context of family accommodation, it seems that parents who have high levels of CFC would be less likely to engage in accommodation despite the short-term costs of refraining from accommodation, such as personal distress resulting from empathic concern, aggressive behavior or expressions of anger from the child, and greater child functional impairment. Parents who have low levels of CFC might be especially likely to accommodate their children's symptoms because in the moment, they have difficulty appreciating the long-term benefits of refraining from accommodation regardless of whether or not they have been provided with psychoeducation about these benefits. Evidence that family accommodation is, in fact, negatively associated with CFC would suggest that it might be worthwhile to explore the benefit of incorporating motivational interviewing techniques to enhance family-based treatment of pediatric OCD.

Beliefs about accommodation. To summarize, clinical observations suggest that parents engage in accommodating behaviors in order to reduce the child's distress and the time that he/she spends engaging in rituals, and to decrease associated impairment 
(Storch et al., 2007a; Merlo et al., 2009). Results of an empirical study of family accommodation of OCD in adults and children are partially consistent with these clinical observations. Calvocoressi et al. (1999) found that $75 \%$ of parents reported that the client would spend more time completing rituals if the family did not accommodate them. However, $66 \%$ of parents believed that accommodation did not alleviate the client's distress and 50\% believed that it did not improve functioning. More research is needed to assess reasons parents offer for engaging in accommodation and their beliefs about the consequences of their behavior. According to Merlo et al. (2009), most parents are unaware that accommodation directly leads to increases in symptom severity; however, this assumption has not been evaluated empirically. Assessing parent beliefs about accommodation would help to identify the relative benefits of specific family-based treatment strategies. For example, motivational interviewing is likely to be more valuable than psychoeducation if parents already understand that accommodation has negative consequences for their child.

\section{Hypotheses}

The following hypotheses were examined in this study:

1. The child's obsessive-compulsive symptom severity will be positively associated with his/her functional impairment. This relationship will be mediated by family accommodation.

2. Parental anxiety will be positively associated with accommodation. This relationship will be mediated by child internalizing symptoms.

3. Parental depression will be positively associated with accommodation. This relationship will be mediated by child externalizing symptoms. 
4. Parental empathy will be positively associated with accommodation. This relationship will be moderated by consideration of future consequences such that empathy will be more strongly associated with accommodation when parents give relatively little consideration to future consequences.

5. Parents whose children exhibit multiple symptom types will report that they most often accommodate symptoms other than hoarding.

6. On average, parents will indicate that they accommodate their child's symptoms in order to reduce his/her distress, reduce the time that he/she spends engaging in rituals, and minimize impairment in academic and/or social functioning.

7. On average, parents will indicate that they believe accommodation has positive short-term consequences for their family but negative long-term consequences. 


\section{Method}

\section{Participants}

Sixty-five children and adolescents with OCD and their parents were recruited from a university-based specialty clinic in the southeastern United States. The participation rate was approximately $96 \%$. Exclusion criteria were the presence of mental retardation or psychotic symptoms in the child, or any psychiatric condition in the parent that would limit the capacity to provide informed consent. Youth participants ranged in age from 6 to 17 years $(M=11.69, S D=3.16)$. Thirty-nine percent of youth were female. The majority of youth were identified by their parents as non-Hispanic White $(85 \% ; n=59)$, with the remaining identified as Hispanic/Latino $(n=4)$, Asian $(n=$ 3), Native Hawaiian/Other Pacific Islander $(n=1)$, and biracial $(n=1)$.

Approximately $62 \%$ of youth participants met criteria for at least one additional diagnosis (35\% met criteria for two or more additional diagnoses). Thirty-one percent of the youth had a comorbid anxiety disorder, 23\% had a comorbid disruptive behavior disorder, $20 \%$ had a comorbid obsessive-compulsive spectrum disorder (i.e., trichotillomania, impulse-control disorder/skin picking, body dysmorphic disorder, or a tic disorder), and $12 \%$ had a comorbid mood disorder. Relatively few youth in this sample had Asperger's disorder $(n=4)$, an elimination disorder $(n=2)$, or an eating disorder $(n=1)$. Approximately $58 \%$ of youth were taking psychotropic medication and $54 \%$ had seen a mental health professional prior to participating in the study. 
Eighty-three percent of caregivers who participated in the study were the child's biological mother and $15 \%$ were the child's biological father; one caregiver (2\%) was the child's stepmother. The majority of parent respondents (86\%) were married or cohabitating. Approximately $60 \%$ of caregivers were employed at the time that they participated in the study; an additional $23 \%$ identified themselves as homemakers. A range of education levels was represented; however, more than half of adult participants $(55 \%)$ had graduated from a four-year college/university, with $17 \%$ having earned a graduate degree. Approximately 19\% of participants reported a combined household income of less than $\$ 50,000,37 \%$ of families had an income between $\$ 50,000$ and $\$ 100,000$, and $44 \%$ had an income over $\$ 100,000$.

The sample size for this study was determined based on effect sizes reported in the literature on family accommodation and on an assessment of feasibility. Studies targeting children and adolescents with OCD have traditionally used modest-sized samples given the relatively low prevalence rates of this disorder (e.g., Rapoport et al., 2000). For example, Storch et al. (2007a) and Peris et al. (2008) examined correlates of accommodation using samples of 57 and 65 parent-child dyads, respectively, and reported medium to large effects.

Diagnoses were determined by a licensed clinical psychologist with expertise in the treatment of OCD, based on a clinical interview and according to criteria outlined in the Diagnostic and Statistical Manual of Mental Disorders-Fourth Edition (Text Revision; American Psychiatric Association, 2000). In 72\% $(n=47)$ of the cases, diagnoses were confirmed using either the Anxiety Disorders Interview Schedule for Children—Child and Parent Version (Silverman \& Albano, 1996) or the Schedule for 
Affective Disorders and Schizophrenia for School Age Children-Present and Lifetime Version (K-SADS-PL; Kaufman, Birmaher, Brent, Rao, \& Ryan, 1997), which was administered by a trained research assistant as part of a series of internally and externally funded studies. For the other $28 \%(n=18)$ of cases, diagnoses were confirmed by the principal investigator using case notes generated by the interviewing psychologist during the intake evaluation (kappa $=1.00)$.

Measures

Background questionnaire. A brief questionnaire was administered to parents in order to collect basic demographic data such as the child's age, gender, race/ethnicity, and living situation in addition to information about the age of onset of OCD, the child's service utilization history, and his/her medication status.

Anxiety Disorders Interview Schedule for DSM-IV: Child and Parent Version (Silverman \& Albano, 1996). The Anxiety Disorders Interview Schedule for DSM-IV: Parent Version (ADIS-P) is a clinician-administered semi-structured diagnostic interview that assesses major DSM-IV anxiety disorders and associated psychopathology (i.e., disruptive behavior disorders, psychotic disorders, and eating disorders) in school-aged children and adolescents. Severity ratings are assigned using a scale that ranges from 0 to 8, with 4 indicating a clinically significant disorder. The ADIS-P takes approximately 45 to 60 minutes to administer.

The ADIS-P has excellent inter-rater agreement for anxiety disorder diagnoses $($ kappa $=.78$ to $.86 ;$ Lyneham, Abbott, \& Rapee, 2007). Test-retest reliability estimates for one- to two-week intervals are adequate to excellent across all anxiety disorders, with kappa coefficients ranging from .65 to .88 (Silverman, Savedra, \& Pina, 2001). Wood et 
al. (2002) provided evidence for the concurrent validity of the ADIS-P, reporting strong correspondence between the individual anxiety diagnoses produced by the ADIS-P and empirically derived subscales form the Multidimensional Anxiety Scale for Children (March, Parker, Sullivan, Stallings, \& Conners, 1997). Also, studies have consistently demonstrated that the ADIS-P is sensitive to treatment effects (e.g., Storch et al., 2008b; Storch et al., 2007b; Storch, Geffken, Adkins, Murphy, \& Goodman, 2007).

Schedule for Affective Disorders and Schizophrenia for School Age ChildrenPresent and Lifetime Version. The Schedule for Affective Disorders and Schizophrenia for School Age Children—Present and Lifetime Version (K-SADS-P/L; Kaufman et al., 1997; Ambrosini, 2000) is a semi-structured interview that assesses 32 child psychiatric disorders organized into five domains: (1) Affective Disorders, (2) Psychotic Disorders, (3) Anxiety Disorders, (4) Behavioral Disorders, and (5) Substance Abuse, Eating, and Tic Disorders. Parents and children are interviewed separately and clinical judgment is used to synthesize a best rating for each item, which ranges from 0 (no information available) to 3 (threshold criteria met). The clinician scores each diagnosis as "Definite," "Probable," (75\% of symptom criteria are met) or "Not present." Administration time ranges from 40 to 75 minutes for each interview, depending on the extent of psychopathology. The K-SADS-P/L includes a screener for 82 key symptoms, allowing the clinician to skip items about non-significant symptoms for a particular disorder once it's determined that the threshold for clinical diagnosis is not met.

The K-SADS-P/L has excellent inter-rater reliability; Kaufman et al. (1997) reported $98 \%$ agreement for both present and lifetime diagnoses. Test-retest reliability coefficients for intervals of two to 38 days ranged from $r=0.78$ to $r=0.90$ and test-retest 
agreement, which was reported for present-episode disorders, ranged from $93 \%$ to $100 \%$. Concurrent validity was established using self- and parent-report questionnaires such the Screen for Child Anxiety Related Emotional Disorders (Birmaher et al., 1997) and the Child Behavior Checklist (Acehnbach \& Edelbrock, 1983).

Children's Yale-Brown Obsessive-Compulsive Scale. The Children's Yale-Brown Obsessive-Compulsive Scale (CY-BOCS; Scahill et al., 1997) is a clinician-rated, semistructured inventory of the presence/absence of 62 obsessive-compulsive symptoms. Ten items are used to assess the severity (i.e., distress, frequency, interference, and resistance) of symptoms over the past week and the extent to which the child can control them. Items are rated on a 5-point Likert-type scale and ratings are summed to produce a Total Score (ranging from 0 to 40) as well as Obsessions Severity and Compulsions Severity scores (each ranging from 0 to 20 ).

The CY-BOCS has good internal consistency, with Cronbach's alpha coefficients ranging from .87 to .90 for the Total Score (Scahill et al., 1997; Storch et al., 2004). For the current sample, Cronbach's alpha was .73. Inter-rater reliability has been demonstrated for the Total Score $(\mathrm{ICC}=.84)$ as well as Obsessions Severity $(\mathrm{ICC}=.91)$ and Compulsions Severity (ICC =.66; Scahill et al., 1997). Inter-rater reliability in this sample was excellent $(\mathrm{ICC}=.97)$. Good test-retest reliability at six weeks has been reported for the all three scores (ICC $=.70$ to .79; Storch et al., 2004). Storch et al. (2004) demonstrated convergent and divergent validity. Scores on the CY-BOCS were strongly associated with clinician-rated measures of impairment, obsessions, and compulsions and moderately related to a self-report measure of depression and clinician ratings of aggression as well as symptoms of Attention-Deficit/Hyperactivity Disorder. 
CY-BOCS scores were not significantly related to clinician ratings of tics or self reports of general anxiety.

Child Obsessive-Compulsive Impact Scale-Revised. The parent-report version of the Child Obsessive-Compulsive Impact Scale-Revised (COIS-R/P; Piacentini et al., 2007; Piacentini \& Jaffer, 1999) was administered. It consists of 33 items that assess the extent to which pediatric OCD has caused impairment in specific areas of psychosocial functioning over the past month: School (6 items), Family/Activities (9 items), Social (13 items), and Daily Living Skills (5 items). Respondents are asked to use a four-point Likert-type scale ranging from 0 (not at all) to 3 (very much). Sample items include "completing assignments in class," "getting along with brothers and sisters," "eating lunch with other kids," and "getting ready for bed at night."

In support of the validity of the COIS-R/P, total and subscale scores were significantly associated with clinician ratings on the Children's Global Assessment Scale (Shaffer et al., 1983) even when controlling for OCD severity and comorbid internalizing and externalizing symptomatology (Piacentini et al., 2007). Two-week test-retest reliability was excellent for the total and subscale scores, with intraclass correlation coefficients ranging from .80 to .88 . Cronbach's alpha coefficient for the current sample was .94.

Child Behavior Checklist. The Child Behavior Checklist/6-18 (CBCL; Achenbach \& Rescorla, 2001) is a parent-report measure of childhood internalizing and externalizing symptoms over the past six months. It consists of 118 items that are rated on a 3-point scale, ranging from 0 (not true) to 3 (very true or often true). In addition to a Total Score, the CBCL yields an Internalizing Problems Composite Score, which is calculated using 
items from three subscales (Withdrawn, Somatic Complaints, Anxious/Depressed), and an Externalizing Problems Composite Score, which is calculated using items from two subscales (Delinquent Behavior, Aggressive Behavior). The psychometric properties of the CBCL have been examined extensively across a variety of clinical and nonclinical populations (Achenbach, 1991; Achenbach \& Rescorla, 2001). Cronbach’s alpha coefficients for the Internalizing Behavior and Externalizing Behavior scores were .90 and .94 , respectively, in the most recent standardization sample (Acehnbach \& Rescorla, 2001). Test-retest reliability was also excellent, with Pearson correlation coefficients of .91 and .92 at one year. Internal consistency reliability estimates for the current sample were .88 for Internalizing Behavior and .91 for Externalizing Behavior.

Brief Symptom Inventory. The Brief Symptom Inventory (BSI; Derogatis, 1993; Derogatis \& Melisaratos, 1983) is a 53-item self-report questionnaire that measures current psychopathology along nine dimensions. For the purposes of this study, symptoms were assessed along two dimensions only: Anxiety and Depression. Each dimension includes six items. Respondents are instructed to indicate how distressed they were during the past week using a five-point Likert-type scale, with response options ranging from 0 (not at all) to 4 (extremely). Responses are averaged to produce a score for each dimension. The approximate completion time for these dimensions is five minutes.

Derogatis (1993) reported reliability estimates of .81 and .85 for the Anxiety and Depression dimensions, respectively (Derogatis, 1993). In the current sample, Cronbach's alpha coefficient was .87 for Anxiety and .82 for Depression. Pearson's correlation coefficients for two-week test-retest reliability were $.85, .79$, and .85 . With 
respect to validity, Derogatis and Melisaratos (1983) demonstrated a theoretically coherent pattern of association between the symptom dimensions of the BSI and scales of the Minnesota Multiphasic Personality Inventory (Hathaway \& McKinley, 1940).

Interpersonal Reactivity Index. Empathy was measured using the PerspectiveTaking (PT) and Empathic Concern (EC) scales of the Interpersonal Reactivity Index (Davis, 1983). Each of these scales requires participants to respond to seven statements using a 5-point Likert-Type scale, with response options ranging from $\mathrm{A}$ (does not describe me well) to $\mathrm{E}$ (describes me well). The PT scale reflects the cognitive component of empathy and consists of items that assess the tendency to spontaneously adopt the point of view of others (e.g., "When I'm upset at someone, I usually try to 'put myself' in his shoes for awhile.") The EC scale reflects the affective component of empathy and consists of items that assess the degree to which the respondent experiences feelings of warmth, compassion, and concern for others (e.g., "I am often quite touched by things that I see happen.”)

Adequate internal consistency was demonstrated in the validation study; Cronbach's alpha coefficients were .73 and .71 for the PT and EC scales, respectively (Davis, 1980). In the current study, items from these scales were combined to form a single measure of empathy, which had a Cronbach's alpha coefficient of .89. Test-retest reliability coefficients for the IRI have ranged from .62 to .72 (Davis, 1980). Convergent and divergent validity have been established (Davis, 1983). Specifically, PerspectiveTaking was found to be related to interpersonal functioning and self-esteem but not to emotionality. Empathic Concern scale was associated with emotionality and a selfless concern for the welfare of others but not with social competence or self-esteem. 
Consideration of Future Consequences Scale. The Consideration of Future Consequences Scale (CFC Scale; Strathman et al., 1994) measures the extent to which individuals consider the potential distant outcomes of their current behaviors and the extent to which they are influenced by these potential outcomes. It consists of 12 items rated on a 5-point Likert-type scale with response options ranging from 1 (extremely uncharacteristic) to 5 (extremely characteristic). Total scores range from 12 to 60 , with a low score representing a focus on immediate needs and concerns. Sample items include "I consider how things might be in the future, and try to influence those things with my day to day behavior" and "My convenience is a big factor in the decisions I make or the actions I take" (reverse-scored).

In the original validation study, Cronbach's alpha coefficients ranged from .80 to .86 (Strathman et al., 1994). For the current sample, Cronbach's alpha coefficient was .88. Strathman et al. (1994) reported test-retest reliability coefficients that ranged from .72 to .76 for five-week and two-week intervals, respectively. Convergent and divergent validity were demonstrated using measures of deferment of gratification, locus of control, and future orientation. Also, high scores on the CFC scale predicted membership in student organizations involved in social causes as well as unfavorable attitudes toward offshore oil drilling, a practice considered to have short-term advantages and long-term disadvantages. Finally, incremental validity was established by demonstrating that scores on the CFC scale predicted a significant amount of unique variance in measures of environmentalism and concern for health over and above related individual-difference measures such as conscientiousness. 
Family Accommodation Scale. Family accommodation was measured using a subset of items from the Family Accommodation Scale (FAS; Calvocoressi et al., 1995). This measure consists of 13 clinician-rated items that assess accommodation in the previous month. Nine of the 13 items tap into the behavioral involvement of family members in the child's OCD (e.g., participation in rituals, modification of daily routines) and the other 4 items assess the level of distress or impairment that family members experience as a result of accommodating or nor accommodating the individual with OCD. Items are scored on a 5-point Likert-type scale, with response options ranging from 0 (never/not at all) to 4 (every day/extreme), and yield a total score that ranges from 0 to 52 .

Adequate internal consistency has been established for the FAS Total Score; Cronbach's alpha has ranged from .76 to .90 (Calvocoressi et al., 1995; Storch et al., 2007a). The FAS has good interrater reliability, with intraclass correlation coefficients for individual items ranging from .72 to 1.0 (Calvocoressi et al., 1999). In support of the validity of the FAS, the total score has been positively associated with symptom severity and familial stress, and negatively associated with family functioning (Calvocoressi et al., 1995). Parent-report and self-report versions of the FAS that are identical in scoring and content to the clinician-rated version and have been used with reports of good internal consistency and test-retest reliability (Stewart et al., 2008a; Peris et al., 2008; Geffken et al., 2006; Merlo et al., 2009). A subscale score representing the nine items that assess behavioral involvement in rituals has been used in previous studies, with good internal consistency (Cronbach's alpha $=.88$; Peris et al., 2008). Cronbach's alpha for this subscale was .80 in the current sample. 
Parent beliefs questionnaire. Parents' beliefs about the short-term and long-term consequences of accommodation were assessed using an 8-item questionnaire developed for use in this study. Response options range from 1 (not at all true) to 5 (very true). Sample items include "I accommodate my child's symptoms to keep his/her OCD from interfering with social activities" and "My child's OCD would improve if I did not accommodate his/her symptoms." Accommodation was defined for participants verbally based on the behaviors that they endorsed on the FAS.

\section{Procedure}

Recruitment of participants. Participants were recruited immediately following the intake evaluation with the director of an internationally known OCD treatment program, who is a licensed psychologist and experienced in the assessment and treatment of OCD. When more than one parent presented to the initial interview, the individual who spends the most time with the identified client was invited to participate in the study. The principal investigator and/or a trained research assistant provided information to parents and their children about the purpose of the study, the type of data collected, and the risks and benefits of participating. Confidentiality and its limits (reports of danger to self, danger to others, abuse) were explained and potential participants were assured that the services they receive at the specialty clinic would not be affected by their decision about whether or not to participate in the research study. All recruitment and consent/assent procedures were approved by the university's Social and Behavioral Institutional Review Board (IRB). Adult informed consent and parental authorization to collect, use, and share the child's health information were documented. For children 7 to 11 years of age, verbal assent was obtained using a script and noted in the research 
record. Written documentation of assent was obtained from children 12 years of age or older.

Data collection. Prior to the start of data collection, research assistants were trained to a reliable standard on the ADIS-P, the K-SADS, and the CY-BOCS through didactics, joint interviews, and supervision discussion. A protocol was followed for each interview and participants' responses were recorded using paper copies of the measures. Research assistants began by reminding participants that they are free to withdraw from the study at any time. Diagnostic interviews (i.e., the ADIS-P or the K-SADS) were administered to each parent. The CY-BOCS was administered to each parent-child dyad. Self-report measures were then administered to the parent in the following order: background questionnaire, COIS-R/P, CBCL, BSI, CFC, and IRI. The clinician-rated FAS was administered and the research assistant prompted the parent to select from the symptoms endorsed on the CY-BOCS which symptom the parent accommodated most frequently. The parent beliefs questionnaire was administered last. The research assistant used information provided on the FAS to formulate instructions for the parent beliefs questionnaire; specifically, "accommodate" was defined for participants based on previously endorsed accommodating behaviors (e.g., providing items, such as hand sanitizer, for the child's compulsions).

This study followed strict guidelines for maintaining confidentiality and securing data. Each parent-child dyad that was consented into the study was assigned a unique identifier that was used in lieu of names in all data files. All identifying information was maintained in a separate, locked file (apart from research data) and electronic files were password protected. Data were collected by research personnel in a manner that did not 
interfere with treatment. Only individuals who were in compliance with the IRB had access to the study data.

Analytic strategy. Structural Equation Modeling (SEM) was used to examine hypotheses 1 through 4. Advantages of SEM over traditional regression models include the ability to model constructs as latent variables, accounting for measurement error in observed variables. The constructs of interest in this study (e.g., functional impairment) were considered latent variables. Total scores on the measures of these constructs (e.g., COIS-R/P) were used as single indicator variables. Means and standard deviations were calculated and a correlation matrix was produced to examine associations among the indicator variables. Although data would typically be assessed for skewness and kurtosis (Mardia, 1970, 1985), these tests produce unreliable information with small samples and thus, were not conducted.

Hypothesized pathways were tested using LISREL 8.80 (Joreskog \& Sorbom, 2006). LISREL generates standardized estimates of all parameters not constrained to specific values. The maximum likelihood (ML) method of parameter estimation was utilized because it produces the highest likelihood of fit and can be used with data that are slightly non-normal. Also, estimates produced by the ML method are consistent and asymptotically efficient (i.e. sampling variance is minimal; Bollen, 1989).

In LISREL, the fit of the hypothesized model to the data is estimated by comparing the model-reproduced covariance matrix, which is based on the specified constraints, with the observed covariance matrix. For this study, models were evaluated for convergence using absolute, incremental, residual-based, and population-based fit indices (Kline, 2005). The goodness of fit index (GFI) is an absolute fit index that 
represents the proportion of variability in the sample covariance matrix explained by the model. The GFI ranges from 0 to 1 , with values of .9 or greater indicating good fit (Joreskog \& Sorbom, 1996). The comparative fit index (CFI) is an incremental fit index that involves assessing fit relative to an independence or null model using a noncentrality parameter, which can be estimated as $\chi^{2}-d f$ (Bentler, 1988). The CFI ranges from 0 to 1, with values greater than or equal to .9 indicating good fit. The standardized root mean square residual (SRMR) is a residual-based fit index that represents the average of the differences between the observed correlations and the estimated correlations. It ranges from 0 to 1 , with values less than or equal to .09 indicating good fit ( $\mathrm{Hu} \&$ Bentler, 1999). The root mean square error of approximation (RMSEA; Steiger, 1990) is a population-based index that involves analysis of residuals and reflects the lack of fit due to reliability and model misspecification (Browne \& Cudeck, 1993). The RMSEA indicates fit per degree of freedom of the model; a value of less than .08 is considered acceptable, with values of .05 or lower indicating very good fit. LISREL provides a $p$ value for a 'test of close fit,' which examines the null hypothesis that the RMSEA is no greater than .05 . (If $p<.05$, it can be concluded that there is a lack of close fit.)

To improve the hypothesized model, standardized residuals, modification indices, and expected change values were inspected. The standardized residual matrix reflects the difference between the observed covariance matrix and the reproduced covariance matrix. A modification index shows the minimum decrease in $\chi^{2}$ if a previously fixed parameter is freed and the model is re-estimated; values greater than 3.84 (the critical value of $\chi^{2}$ with $d f=1$ at alpha $\left.=.05\right)$ are considered large. Expected change values are the expected values of the parameters if they are freed. Modifications (i.e., the addition 
or deletion of paths) for which a clear interpretation could be offered were considered. Trivial and non-significant relationships among exogenous variables, which were allowed to correlate freely in the original model, were fixed (i.e., set to 0 ) in the final model, increasing the degrees of freedom for hypothesis testing.

Hypotheses 1 through 3 were examined using tests of significance for indirect effects (Sobel, 1982), which refer to the influence of an independent variable (e.g., parent anxiety) on a dependent variable (e.g., family accommodation) as mediated by one or more intervening variables (e.g., child internalizing problems). Hypothesis 4, which involves latent variable interaction, was tested according to the procedure outlined by Ping (1996). This procedure involves estimating error variances for the indicators of latent variables (i.e., parent empathy and $\mathrm{CFC}$ ), creating an interaction latent variable by forming a product of the indicators of latent variables (Kenny \& Judd, 1984), using error variances for these indicators to calculate the error variance of the interaction latent variable, and specifying the resulting error variance as a constant in the structural model containing the interaction variable.

Hypothesis 5 was addressed using data from parents whose children exhibited more than one of five types of compulsions: cleaning, checking, repeating/counting/ordering, hoarding, and reassurance seeking. For each type of compulsion, a percentage was calculated by dividing the number of parents who selected a compulsion of that type as the symptom they accommodate most frequently by the number of parents whose children exhibit the compulsion type (and at least one other), as assessed using the CY-BOCS. In order to address hypotheses 6 and 7, means and 
standard deviations as well as frequencies are reported for each item on the on the measure of parent beliefs about accommodation. 


\section{Results}

\section{Preliminary Analyses}

Missing data. Cases were excluded from LISREL analyses if they were missing responses to more than half of the items from any measure used to test hypotheses 1 through 4. The resulting sample consisted of 61 parent-child dyads. Across these cases, the number of observations missing from each measure ranged from 0 to 4 . (The number of observations possible ranged from 366 to 2074). Measures were scored by averaging responses across the items that make up each scale. For hypotheses 5 through 7, cases with any data missing from measures of relevant variables were excluded; complete data were available for 62 parent-child dyads.

Descriptive statistics. Descriptive statistics and correlations among indicator variables in the structural equation model are presented in Table 1. Internal consistency estimates for the indicator variables are displayed on the diagonal. Given that latent variables were represented by single indicators with high levels of reliability (alphas > .70), the measurement model is considered adequate.

Model fit. The minimum fit function chi-square for the hypothesized model was significant, $\chi_{\mathrm{M}}^{2}(21)=35.84, p=.02$, reflecting less than adequate fit. With the exception of the RMSEA, other fit indices suggest that the model fit the data reasonably well (see Table 2). The second model that was tested was identical to the first model except that trivial and non-significant associations among exogenous variables were fixed. The second model yielded a chi-square that was not significant, $\chi^{2}{ }_{\mathrm{M}}(30)=39.845, p=.11$. 
Table 1

Zero Order Correlations, Means, Standard Deviations, and Reliability Estimates for Indicators

\begin{tabular}{|c|c|c|c|c|c|c|c|c|c|}
\hline & 1. & 2. & 3. & 4. & 5. & 6. & 7. & 8. & 9. \\
\hline 1. BSI Anxiety & .87 & & & & & & & & \\
\hline 2. BSI Depression & $.53 *$ & .82 & & & & & & & \\
\hline 3. IRI & -.06 & -.24 & .89 & & & & & & \\
\hline 4. CFC & -.07 & -.18 & $.49 *$ & .88 & & & & & \\
\hline 5. CY-BOCS & .20 & .12 & -.05 & .06 & .73 & & & & \\
\hline 6. CBCL Internalizing & $.31 *$ & $.37 *$ & -.15 & -.10 & .21 & .87 & & & \\
\hline 7. CBCL Externalizing & .10 & .25 & $-.33 *$ & -.16 & .08 & $.48 *$ & .88 & & \\
\hline 8. COIS-R/P & .19 & .19 & -.05 & .12 & $.54^{*}$ & $.64 *$ & $.35^{*}$ & .94 & \\
\hline 9. FAS & .15 & .01 & -.03 & .08 & $.53 *$ & $.43^{*}$ & $.37 *$ & $.57 *$ & .80 \\
\hline $\begin{array}{l}\text { Mean } \\
(\mathrm{SD})\end{array}$ & $\begin{array}{c}0.75 \\
(0.78) \\
\end{array}$ & $\begin{array}{c}0.49 \\
(0.64) \\
\end{array}$ & $\begin{array}{c}2.99 \\
(0.63) \\
\end{array}$ & $\begin{array}{c}3.65 \\
(0.73) \\
\end{array}$ & $\begin{array}{c}2.33 \\
(0.45) \\
\end{array}$ & $\begin{array}{c}0.45 \\
(0.30) \\
\end{array}$ & $\begin{array}{c}0.30 \\
(0.27) \\
\end{array}$ & $\begin{array}{c}0.86 \\
(0.60) \\
\end{array}$ & $\begin{array}{c}1.56 \\
(0.88) \\
\end{array}$ \\
\hline
\end{tabular}

Note. $n=61$ parent-child dyads. Cronbach's alphas are listed on the diagonal. BSI = Brief Symptom Inventory (0-4); IRI = Interpersonal Reactivity Index (0-4); CFC = Consideration of Future Consequences Scale (1-5); CY-BOCS = Children's Yale-Brown Obsessive Compulsive Inventory (0-4); CBCL = Child Behavior Checklist (0-2); COIS-R/P = Child Obsessive-Compulsive Impact Scale-Revised, Parent Report (0-3); FAS = Family Accommodation Scale (0-4).

$* p<.05$ 
Table 2

Summary of Model Fit Statistics

\begin{tabular}{lllllll}
\hline Model & $\chi^{2}$ & $d f$ & RMSEA & SRMR & CFI & GFI \\
\hline $\begin{array}{l}\text { Hypothesized } \\
\text { Model }\end{array}$ & 35.944 & 21 & 0.129 & 0.080 & 0.886 & 0.885 \\
$\begin{array}{l}\text { Parsimonious } \\
\text { Model }\end{array}$ & 39.845 & 30 & 0.093 & 0.096 & 0.914 & 0.876 \\
\hline
\end{tabular}

Note. $n=61$ parent-child dyads. RMSEA = root mean square error of approximation; $\mathrm{SRMR}=$ standardized root mean square residual $; \mathrm{CFI}=$ comparative fit index; $\mathrm{GFI}=$ goodness of fit index.

The RMSEA was much improved, with the test of close fit $(p=.108)$ indicating that this index did not differ significantly from the .05 standard of very good fit. The CFI was also good; the GFI and SRMR were reasonable. The second model did not differ significantly from the first model in terms of fit $\left[\chi_{\text {difference }}^{2}(9)=3.901, p=.92\right]$ but was retained based on the consideration of parsimony. An examination of the 55 standardized residuals revealed that they were normally distributed and with the exception of 1 , they were all smaller than \pm 2.58 . Standardized parameter estimates for the final model are displayed in Figure 2. Included are estimates of measurement error and structural coefficients corrected for attenuation.

Hypothesis Testing

Standardized total effects of the latent variables on each other are presented in Table 3. The final solution explained over $80 \%$ of the variance (1-.188) in family accommodation. Results corresponding to individual hypotheses are discussed below. 


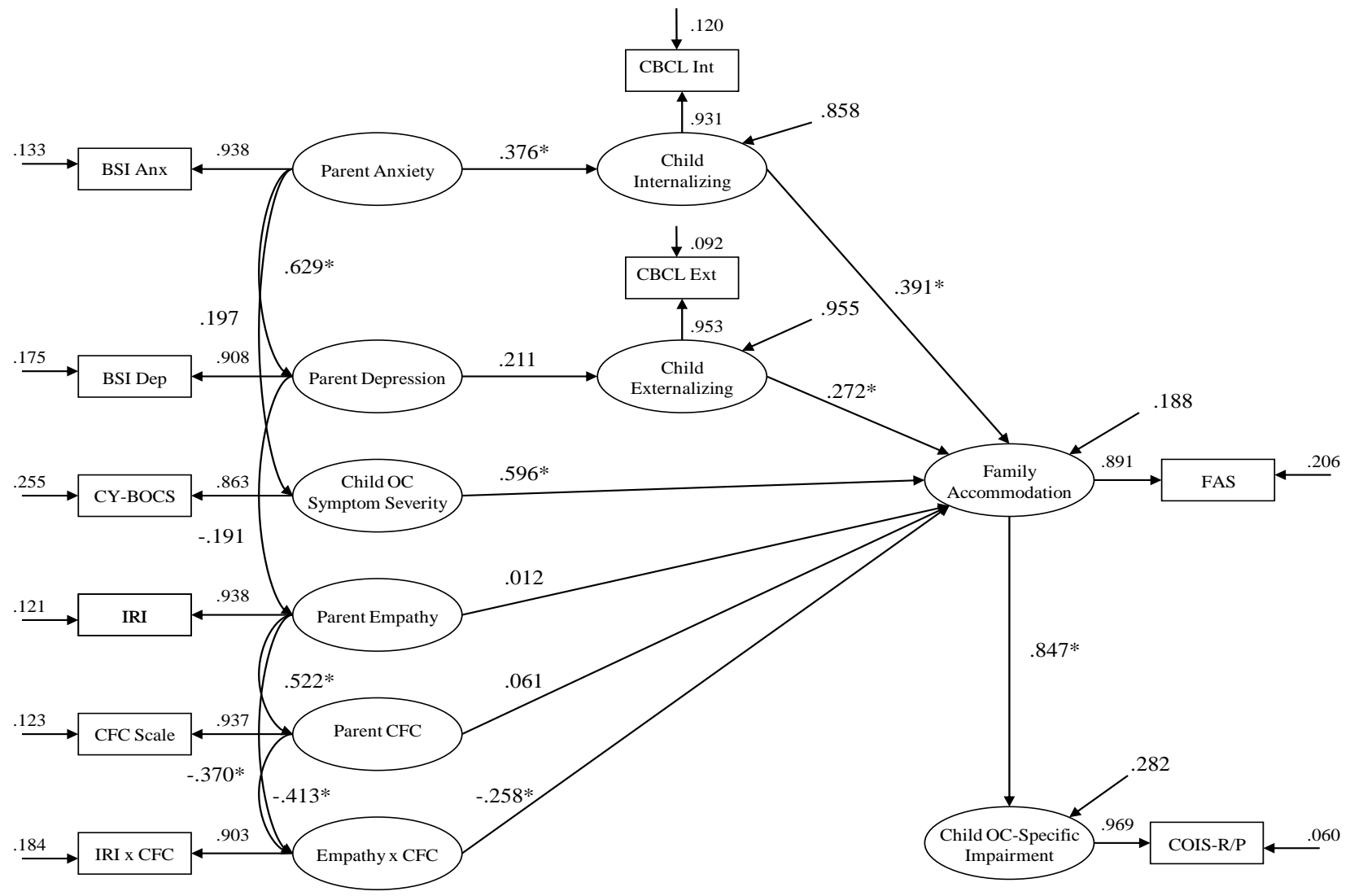

Figure 2. Final structural equation model $(n=61)$. Standardized path coefficients are reported. BSI = Brief Symptom Inventory; IRI = Interpersonal Reactivity Index; CFC = Consideration of Future Consequences Scale; CY-BOCS = Children's Yale-Brown Obsessive Compulsive Inventory; $\mathrm{CBCL}=$ Child Behavior Checklist; COIS-R = Child Obsessive-Compulsive Impact Scale-Revised, Parent Report; FAS = Family Accommodation Scale.

$* p<.05$ 
Table 3

Standardized Total Effects among Latent Variables in Final Model

\begin{tabular}{|c|c|c|c|c|c|c|c|c|c|}
\hline & \multicolumn{6}{|c|}{ Exogenous on Endogenous } & \multicolumn{3}{|c|}{ Endogenous on Endogenous } \\
\hline & ANX & DEP & SEV & EMP & $\mathrm{CFC}$ & $\begin{array}{c}\text { EMP x } \\
\text { CFC }\end{array}$ & INT & EXT & $\mathrm{ACC}$ \\
\hline INT & $.376^{*}$ & - & -- & -- & -- & - & -- & -- & -- \\
\hline EXT & -- & .211 & -- & -- & -- & -- & -- & -- & -- \\
\hline $\mathrm{ACC}$ & $.147 *$ & .057 & $.596 *$ & .012 & .061 & $-.258 *$ & $.391 *$ & $.272 *$ & -- \\
\hline IMP & $.124 *$ & .049 & $.505 *$ & .011 & .052 & $-.219 *$ & $.331 *$ & $.230 *$ & $.847 *$ \\
\hline \multicolumn{10}{|c|}{$\begin{array}{l}\text { Note. } \mathrm{ANX}=\text { parent anxiety; } \mathrm{DEP}=\text { parent depression; } \mathrm{SEV}=\text { child } \mathrm{OCD} \text { symptom severity; } \\
\text { EMP = parent empathy; } \mathrm{CFC}=\text { parent consideration of future consequences; INT = child } \\
\text { internalizing problems; } \mathrm{EXT}=\text { child externalizing problems; } \mathrm{ACC}=\text { family accommodation; } \\
\text { IMP = child OCD-specific impairment. } \\
* p<.05\end{array}$} \\
\hline
\end{tabular}


Hypothesis 1. It was hypothesized that child obsessive-compulsive symptom severity would be positively associated with functional impairment and that this relationship would be mediated by family accommodation. This hypothesis was supported. Child obsessive-compulsive symptom severity had a significant indirect effect on child OCD-specific impairment via family accommodation, $t(60)=4.94, p<$ .05. Modification indices did not suggest the addition of a direct path from child obsessive-compulsive symptom severity to OCD-specific impairment (MI $=0.30)$, supporting full mediation.

Hypothesis 2. It was hypothesized that parent anxiety would be positively associated with accommodation and that this relationship would be mediated by child internalizing symptoms. This hypothesis was supported. Parent anxiety significantly influenced child internalizing problems, which in turn, had a significant influence on family accommodation, $t(60)=2.20, p<.05$. Modification indices did not suggest the addition of a direct path from parent anxiety to family accommodation $(\mathrm{MI}=1.93)$, supporting full mediation. Of note is that parent anxiety also had a significant indirect effect on child functional impairment, $t(60)=2.17, p<.05$, suggesting three-path mediation.

Hypothesis 3. It was hypothesized that parent depression would be positively associated with accommodation and that this relationship would be mediated by child externalizing symptoms. This hypothesis was not supported. Although child externalizing problems significantly influenced family accommodation, $t(60)=2.35, p<$ .05 , the path from parent depression to child externalizing problems was not significant. Modification indices suggest that the fit of the model would be improved substantially by 
allowing a direct path from parent depression to family accommodation $(\mathrm{MI}=4.23)$. However, the expected change value $(\mathrm{SEPC}=-.219)$ indicates that the sign of the path coefficient would be negative even though the zero-order correlation between parent depression and accommodation was positive. This situation occurs when there are suppression effects (Conger, 1974; MacKinnon, Krull, \& Lockwood, 2000); thus, a direct path was not added. Had this path been included, it would have inflated the influence of other predictors.

Hypothesis 4. It was hypothesized that parent empathy would be positively associated with accommodation and that this relationship would be moderated by CFC (such that empathy would be more strongly associated with accommodation when parents give relatively little consideration to future consequences). This hypothesis was supported. Parent empathy and CFC did not have significant direct effects on family accommodation; however, as predicted, their interaction was significant, $t(60)=-2.20, p$ $<.05$. Follow up tests of simple slopes (Aiken \& West, 1991) revealed that at low levels of CFC (i.e., one standard deviation below the mean), the relationship between empathy and accommodation was positive and significant, $\beta=.25, t=2.44, p<.05$. That is, among parents who are present-oriented, highly empathic parents accommodate more than parents who score low on measures of empathy. At average and high levels of CFC (i.e., at the mean and one standard deviation above the mean), the slopes were not significant. Figure 3 illustrates these relationships. 


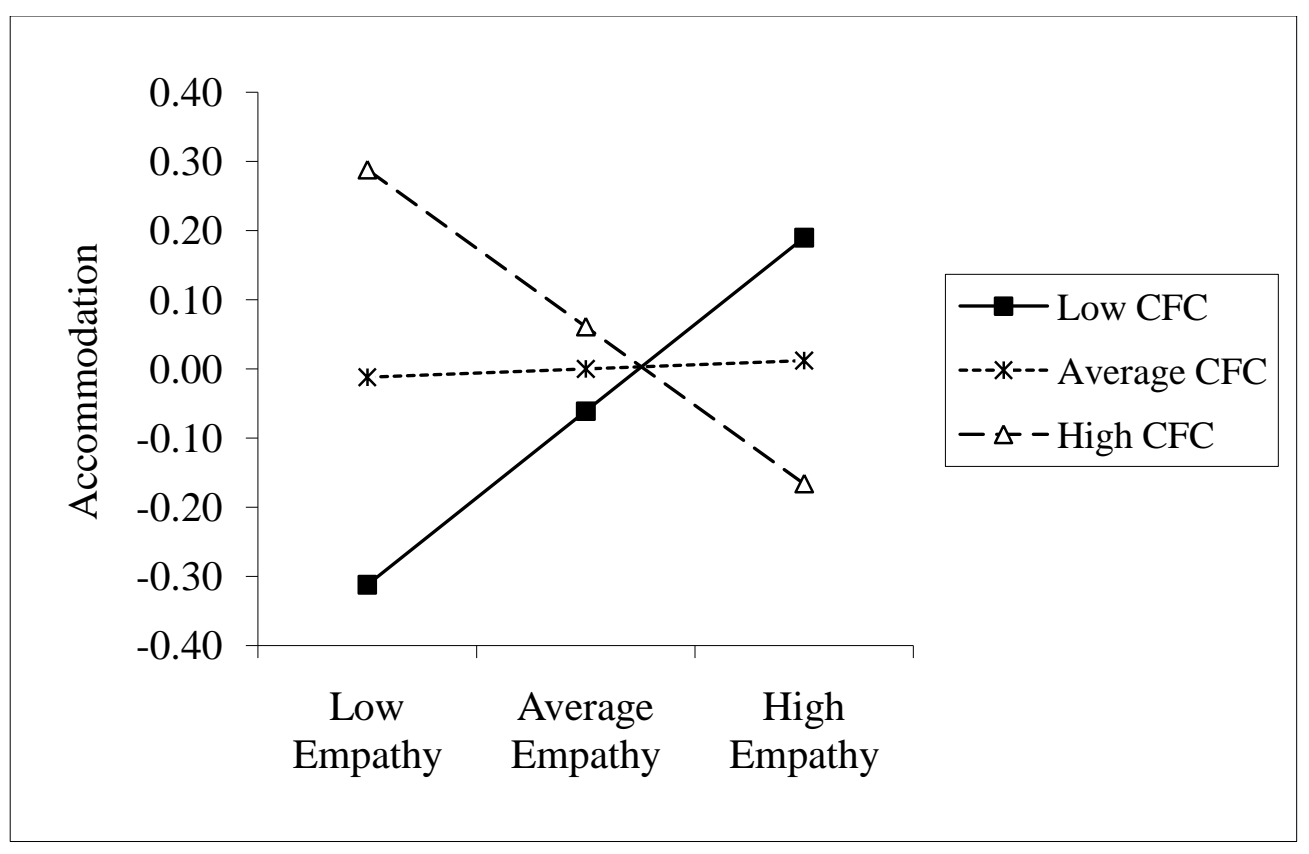

Figure 3. The interaction between parent empathy and consideration of future consequences in the prediction of family accommodation

Hypothesis 5. It was hypothesized that parents whose children exhibit multiple symptom types would report that they most often accommodate symptoms other than hoarding. This hypothesis was supported. Relative frequencies are reported in Table 4. Fifty-one children in the sample exhibited more than one type of compulsion. The majority of their parents whose children exhibited reassurance seeking indicated that they accommodated this compulsion most frequently. Cleaning/washing compulsions were accommodated (over other symptoms) at the second highest rate. Hoarding and checking compulsions generally were not accommodated more frequently than other types of symptoms exhibited by the same children. 
Table 4

Frequencies with which Symptom Types were Exhibited and Accommodated Most Often

\begin{tabular}{lll}
\hline Compulsion type & $\begin{array}{l}\text { Frequency among } \\
\text { youth with } \geq 2 \\
\text { symptom types }\end{array}$ & $\begin{array}{l}\text { Frequency with which } \\
\text { accommodated most }\end{array}$ \\
\hline Cleaning & $37(72.5 \%)$ & $11(29.7 \%)$ \\
Checking & $29(56.9 \%)$ & $0(0.0 \%)$ \\
Repeating/Counting/Ordering & $42(82.4 \%)$ & $5(11.9 \%)$ \\
Hoarding & $16(31.4 \%)$ & $1 \quad(6.3 \%)$ \\
Reassurance seeking & $43(84.3 \%)$ & $23(53.5 \%)$ \\
\hline
\end{tabular}

Note. $n=51$. Youth who exhibited one symptom type only were not included in analyses. Frequencies in the last column were calculated using data from children who exhibited the symptom type in question (not all children who exhibited multiple symptoms types).

Hypothesis 6. It was hypothesized that on average, parents would indicate that they accommodate their child's symptoms in order to reduce his/her distress, reduce the time that he/she spends engaging in rituals, and minimize impairment in academic and/or social functioning. This hypothesis was supported. For each item that assessed these beliefs, mean scores were at or above the midpoint of the scale (which corresponds to somewhat true). Means and standard deviations for each belief are displayed in Table 5. Frequencies are presented in Table 6. Correlations among parent beliefs about accommodation and total accommodation scores are presented in Table 7.

Hypothesis 7. It was hypothesized that on average, parents would indicate that they believe accommodation has positive short-term consequences for their family but negative long-term consequences. When the beliefs that accommodation is helping the child in the present but not in the long run are considered separately, means and frequencies are consistent with this hypothesis (see Tables 5 and 6). However, only $21 \%$ of parents $(n=13)$ indicated that they hold both of these beliefs. By contrast, $50 \%$ of 
parents $(n=31)$ endorsed the belief that accommodation is helping (at least somewhat) in the present and the belief that accommodation is helping in the long-run. The majority of parents $(62.9 \%, n=39)$ indicated that it is at least somewhat true that they engage in accommodation because it would be difficult for their family to get through the day otherwise.

Table 5

Means and Standard Deviations for Parent Beliefs about Accommodation

\begin{tabular}{ll}
\hline Belief & Parents \\
\hline 1. in order to reduce distress & $3.79(1.19)$ \\
2. in order to reduce time spent engaging in rituals & $3.19(1.34)$ \\
3. in order to keep OCD from interfering with school & $3.21(1.53)$ \\
4. in order to keep OCD from interfering with social activities & $2.98(1.50)$ \\
5. it would be difficult for family to get through day otherwise & $3.05(1.49)$ \\
6. is helping child in present & $3.17(1.34)$ \\
7. is helping child in long run & $2.58(1.39)$ \\
8. OCD would improve if did not accommodate & $2.65(1.47)$ \\
\hline Note. $n=62$ parents. Response options range from 1 (not at all true) to $5($ very true).
\end{tabular}


Table 6

Frequencies for Parent Beliefs about Accommodation

\begin{tabular}{lrrrrr}
\hline Belief & 1 & 2 & 3 & 4 & 5 \\
\hline 1. to reduce distress & $3.2 \%$ & $11.3 \%$ & $29.0 \%$ & $16.1 \%$ & $40.3 \%$ \\
2. to reduce time spent engaging in rituals & 14.5 & 14.5 & 30.6 & 17.7 & 22.6 \\
3. to keep OCD from interfering with school & 21.0 & 12.9 & 21.0 & 14.5 & 30.6 \\
4. to keep OCD from interfering with social activities & 25.8 & 11.3 & 24.2 & 16.1 & 22.6 \\
5. it would be difficult to get through day otherwise & 21.0 & 16.1 & 27.4 & 8.1 & 27.4 \\
6. is helping child in present & 16.1 & 12.9 & 29.0 & 21.0 & 21.0 \\
7. is helping child in long run & 32.3 & 16.1 & 24.2 & 16.1 & 11.3 \\
8. OCD would improve if did not accommodate & 32.3 & 16.1 & 24.2 & 9.7 & 17.7 \\
\hline
\end{tabular}

Note. $n=62$ parents. $1=$ not at all true, $3=$ somewhat true, $5=$ very true. 
Table 7

Correlations among Parent Beliefs about Accommodation and Family Accommodation Belief FAS

1. in order to reduce distress $.47 * *$

2. in order to reduce time spent engaging in rituals $.29 *$

3. in order to keep OCD from interfering with school $.38 * *$

4. in order to keep OCD from interfering with social activities $.45^{* *}$

5. it would be difficult for family to get through day otherwise $.60 * *$

6. is helping child in present

7. is helping child in long run

8. OCD would improve if did not accommodate $-.04$

Note. $n=62$ parents. FAS $=$ Family Accommodation Scale.

$* p<.05$

$* * p<.01$ 


\section{Discussion}

This study extends the literature on family accommodation by examining its relationship to a number of theoretically relevant child and parent variables that could be the target of intervention. Additionally, parents' motivations for engaging in accommodation and beliefs about its short- and long-term consequences were assessed, and differences in accommodation by symptom type were explored. A study strength is that structural equation modeling was used to examine multiple relationships simultaneously while accounting for measurement error, providing a more powerful test of hypotheses than multiple regression.

As expected, family accommodation mediated the relationship between child obsessive-compulsive symptom severity and parent-rated functional impairment. Whereas Storch et al. (2007a) found partial mediation using multiple regression techniques, the current study supported full mediation. That is, symptom severity might influence the extent of family accommodation, which in turn, contributes to the level of functional impairment in children, perhaps by limiting their opportunities to develop problem solving skills and putting a strain on relationships with family members (e.g., Steketee \& Van Noppen, 2003). Further, most parents reported that they accommodated OCD symptoms to minimize impairment; half of the parents believed that accommodation was helpful to their child in the present and the long run. Taken together, these findings indicate that educating parents about the negative consequences 
of accommodating behaviors (i.e., their relationship to impairment) might be a necessary first step to decreasing their frequency.

As hypothesized, parent anxiety had a significant indirect effect on family accommodation via child internalizing symptoms. Child externalizing problems also influenced accommodation significantly. These findings are generally consistent with previous studies (Storch et al., 2007a; Peris et al., 2008) and suggest that the treatment of pediatric OCD could be enhanced by addressing comorbid psychopathology in youth and parents. Specifically, addressing parents' anxiety is likely to reduce accommodation by increasing their ability to tolerate exposing their children to feared situations as well as their resources for coping with resulting expressions of distress. Also, treating children's internalizing problems would improve their ability to manage the distress that they experience when accommodation is refused. Finally, providing training in behavior management techniques (e.g., Kazdin, 2005), such as positive reinforcement and response cost, might be necessary to assist parents in refraining from accommodating OCD symptoms in the face of tantrums or other angry responses from their children.

The hypothesis that child externalizing problems would mediate the relationship between parent depression and accommodation was not supported. Parent depression had neither a direct nor an indirect effect on accommodation. It may be that depression does not contribute to accommodation at all. Another possibility is that child externalizing problems has a moderating instead of mediating effect on the relationship between parent depression and accommodation. For depressed parents whose children exhibit defiant or aggressive behavior, it might be easier (i.e., require less energy or cause less disruption) to accommodate OCD symptoms than to refrain from accommodation. However, for 
depressed parents whose children are not oppositional, doing nothing in response to OCD symptoms is likely easier than accommodating them.

There was a significant interaction between parent empathy and consideration of future consequences (CFC) such that at low levels of CFC, empathy was positively associated with accommodation. Parents who were highly empathic and less likely to consider future consequences (e.g., in the face of daily hassles or expressions of distress from their children) exhibited relatively high levels of accommodation. Thus, it might be useful to consider CFC and empathy in exploring parent-focused strategies for targeting accommodating behaviors. Motivational interviewing, for example, focuses on resolving ambivalence about behavior change that has short-term negative consequences but longterm positive consequences. It has shown promise as an adjunct to CBT for pediatric OCD (Merlo et al., 2010). Low levels of CFC have predicted the success of motivational interviewing interventions in other populations (Carey, Henson, Carey, \& Maisto, 2007). These interventions might be effective for parents who continue to accommodate OCD symptoms after being educated about the long-term benefits of refraining from accommodation. Also, given that most parents indicated that they accommodate in an effort to reduce their child's distress (which is an immediate outcome), cognitive distraction techniques (e.g., Linehan, 1993) might be helpful to present-oriented and highly empathic parents who have difficulty disengaging from their child's rituals. Future studies should examine these possibilities.

Although findings with respect to the relationship between OCD symptom type and accommodation are preliminary and should be replicated using larger samples, some noteworthy patterns emerged. Parents of children who exhibited multiple symptom types 
(i.e., cleaning, checking, repeating/counting/ordering, hoarding, reassurance seeking) generally accommodated reassurance seeking more frequently than they accommodated other compulsions. This finding makes sense given that providing verbal reassurance does not necessarily disrupt the family routine and requires minimal response effort. Also, parents might feel some responsibility to accommodate this compulsion if they have difficulty distinguishing it from normal behavior exhibited by children as they learn to discriminate between threatening and non-threatening stimuli. Accordingly, clinicians should routinely assess for the accommodation of reassurance seeking and integrate it into the treatment plan.

Cleaning/washing compulsions were accommodated relatively often, perhaps because they are more likely than symptoms such as checking to require assistance from parents (e.g., in the form of providing necessary items). In addition, rituals that occurred in the bathroom (e.g., while showering) might be difficult to monitor or control and are often accommodated by families altering their daily routine. Finally, clinical observations suggest that it is common for parents of children who present with contamination symptoms to exhibit these symptoms at some level as well. Consequently, parents may be more motivated to accommodate cleaning/washing rituals (versus other types of compulsions) and feel less burdened in doing so. Future studies should examine the correspondence between child and parent symptoms, as it may have important implications for treatment.

Not surprisingly, parents were relatively intolerant of hoarding symptoms. In most cases, it would be difficult to conceal hoarding from parents, who might intervene by discarding the child's possessions in order to prevent clutter in the family's living 
space. Parents' refusal to accommodate hoarding symptoms might explain higher rates of externalizing behaviors among children who exhibit this compulsion (Storch et al., 2007c). Given that hoarding has emerged as distinct from other OCD presentations in numerous ways (e.g., Storch et al., 2007c) and will likely be classified as a separate disorder in the DSM-V (e.g., Mataix-Cols et al., 2010), empirical studies that exclusively sample children with hoarding symptoms are needed to assess the relevance of family accommodation to clinical intervention with this group.

Finally, the majority of parents in this sample indicated that they engage in accommodation to some extent because it would be difficult for their family to get through the day otherwise. This may be especially true for families with more than one child. For example, refraining from accommodating symptoms in the morning may make it difficult for the family to leave home on schedule, causing parents to be concerned that siblings of the child with OCD will be penalized for arriving to school late. Rather than simply instructing parents not to accommodate, clinicians may need to assist them in problem solving around such obstacles to resisting accommodation.

\section{Limitations}

This study had several limitations. First, OCD diagnoses were confirmed using a structured clinical interview for a subset of participants only. However, there was $100 \%$ agreement between two clinicians with expertise in OCD for the remaining cases and CY-BOCS scores were all above 12 (an accepted cutoff for clinically significant symptoms). Second, inter-rater reliability was not assessed for the FAS. However, internal consistency of this measure was .80 , and inter-rater reliability has been established previously (Merlo, Storch, Murphy, Goodman, \& Geffken, 2005). Third, the 
sample was relatively homogeneous demographically, limiting the extent to which findings generalize to the larger population of youth with OCD. Fourth, because the design of this study was cross-sectional, causal effects could not be inferred. Structural equation modeling does not assess causality any more than other statistical techniques. Prospective longitudinal studies are needed to confirm the direction of the relationships found significant. Fifth, the magnitude of some relationships reported in this study might have been inflated by common method variance resulting from the use of parents as central informants. Finally, the effects of variables omitted from the model (e.g., parent obsessive-compulsive symptoms; age of onset of child OCD; previous treatment experiences) are unknown; had they been included, hypothesis testing might have yielded different results. However, given that the model explained over $80 \%$ of the variance in family accommodation, the present findings are likely robust.

\section{Summary}

This study expands the literature underscoring the importance of attending to family accommodation in the treatment of pediatric OCD (Storch et al., 2007a; Peris et al., 2008; Merlo et al., 2009; Storch et al., 2010). Results suggest that accommodation is influenced by child variables (OCD symptom type and severity, comorbid internalizing and externalizing problems) as well as parent variables (anxiety symptoms, empathy, consideration of future consequences), and is linked to heightened functional impairment. Although more research is needed to understand how these relationships emerge over time, the current findings suggest that prescriptive or modularized approaches to intervention with families of children who have OCD might facilitate large reductions in accommodation, which have been associated with positive treatment response (Merlo et 
al., 2009). Modular treatment protocols allow CBT procedures to be applied in a highly individualized manner (Chorpita, Taylor, Francis, Moffitt, \& Austin, 2004). Future studies should explore the utility of brief modules for assisting parents in refraining from accommodation. These modules might focus on psychoeducation about the impact of accommodation, CBT strategies for reducing parent anxiety, behavior management strategies, distraction techniques for tolerating empathic responses to child distress, motivational interviewing, and problem solving around daily hassles that make it difficult to resist accommodating OCD symptoms. 


\section{References}

Abramowitz, J.S., Tolin, D.F., \& Street, G.P. (2001). Paradoxical effects of thought suppression: A meta-analysis of controlled studies. Clinical Psychology Review, $21,683-703$.

Abramson, L., Metalsky, G., \& Alloy, L. (1989). Hopeless depression: A theory-based subtype of depression. Psychological Review, 96, 358-372.

Achenbach, T.M. (1991). Manual for the Child Behavior Checklist/4-18 and 1991 profile. Burlington: University of Vermont, Department of Psychiatry.

Achenbach, T. \& Edelbrock, G. (1983). Manual of the Child Behavior Checklist and Revised Child Behavior Profile. Burlington: University of Vermont Department of Psychiatry.

Achenbach, T.M. \& Rescorla, L. (2001). Manual for the ASEBA School-age Forms and Profiles. Burlington: Research Center for Children, Youth, \& Families.

Aiken, L.S. \& West, S.G. (1991). Multiple regression: Testing and interpreting interactions. Newbury Park, CA: Sage.

Allsopp, M. \& Verduyn, C. (1990). Adolescents with obsessive-compulsive disorder: A case note review of consecutive patients referred to a provincial regional adolescent psychiatry unit. Journal of Adolescence, 13, 157-169.

Ambrosini, P.J. (2000). Historical development and present status of the Schedule for Affective Disorders and Schizophrenia for School-Age Children (K-SADS). Journal of the American Academy of Child and Adolescent Psychiatry, 39, 49-58. 
American Academy of Child and Adolescent Psychiatry (1998). Practice parameters for the assessment and treatment of children and adolescent with obsessivecompulsive disorder. Journal of the American Academy of Child and Adolescent Psychiatry, 37, 27S-45S.

American Psychiatric Association (2000). Diagnostic and statistical manual of mental disorders (Revised 4th ed.). Washington, DC: Author.

Amir, N, Freshman, M., \& Foa, E.B. (2000). Family distress and involvement in relatives of obsessive-compulsive disorder patients. Journal of Anxiety Disorders, 14, 209-217.

Barlow, D.H. (2002). Anxiety and its disorders: The nature and treatment of anxiety and panic (2nd ed.). New York, NY: Guilford Press.

Barrett, P., Farrell, L., Dadds, M., \& Boutler, N. (2005). Cognitive-behavioral family treatment of obsessive-compulsive disorder: Long-term follow-up and predictors of outcome. Journal of the American Academy of Child and Adolescent Psychiatry, 43, 46-62.

Barrett, P., Healy-Farrell, L., \& March, J.S. (2004). Cognitive-behavioral family treatment of childhood obsessive-compulsive disorder: A controlled trial. Journal of the American Academy of Child and Adolescent Psychiatry, 43, 46-62.

Barrett, P.M., Rasmussen, P.J., \& Healy, L. (2001). The effect of obsessive-compulsive disorder on sibling relationships in late childhood and early adolescence: Preliminary findings. The Australian Educational and Developmental Psychologist, 17, 82-102. 
Batson, C.D. (1991). The altruism question: Toward a social-psychological answer. Hillsdale, NJ: Lawrence Erlbaum Associates.

Batson, C.D. \& Coke, J. (1981). Empathy: A source of altruistic motivation for helping. In J. Rushton \& R. Sorrentino (Eds.), Altruism and helping behavior. Hillsdale, NJ: Erlbaum.

Beck, A.T., Rush, A.J., Shaw, B.F., \& Emery, G. (1979). Cognitive therapy of depression. New York, NY: Guilford Press.

Benazon, N.R., Ager, J., \& Rosenberg, D.R. (2002). Cognitive behavior therapy in treatment-naïve children and adolescents with obsessive-compulsive disorder: An open trial. Behaviour Research and Therapy, 40, 529-539.

Bentler, P.M. (1988). Comparative fit indexes in structural models. Psychological Bulletin, 107, 238-246.

Birmaher, B., Khetarpal, S., Brent, D., Cully, M., Balach, L., Kaufman, J. et al. (1997). The Screen for Child Anxiety Related Emotional Disorders (SCARED): Scale construction and psychometric characteristics. Journal of the American Academy of Child and Adolescent Psychiatry, 36, 545-553.

Black, D.W., Goldstein, R.B., Noyes, Jr. R., \& Blum, N, (1995). Psychiatric disorders in relatives of probands with obsessive-compulsive disorder and com-morbid major depression or generalized anxiety. Psychiatric Genetics, 5, 37-41.

Bloch, M.H., Landeros-Weisenberger, A., Rosario, M.C., Pittenger, C., \& Leckman, J.F. (2008). Meta-analysis of the symptom structure of obsessive-compulsive disorder. American Journal of Psychiatry, 165, 1532-1542.

Bollen, K.A. (1989). Structural equations with latent variables. New York, NY: Wiley. 
Bor, W. \& Sanders, M.R. (2004). Correlates of self-reported coercive parenting of preschool-aged children at high risk for the development of conduct problems. Australian and New Zealand Journal of Psychiatry, 38, 738-745.

Browne, M.W. \& Cudeck, R. (1993). Alternative ways of assessing model fit. In: K.A. Bollen \& J.S. Long (Eds.), Testing structural equation models (pp. 136-162). Newbury Park, CA: Sage Publications.

Calvocoressi, L., Lewis B., Harris, M. Trufan, S.J., Goodman, W.K., McDougle, C.J. et al. (1995). Family accommodation in obsessive-compulsive disorder. American Journal of Psychiatry, 152, 441-443.

Calvocoressi, L., Mazure, C.M., Kasl, S.V., Skolnick, J., Fish, D., Vesgo, S. et al. (1999). Family accommodation of obsessive-compulsive symptoms: Instrument development and assessment of family behavior. Journal of Nervous and Mental Disease, 187, 636-642.

Carey, K.B., Henson, J.M., Carey, M.P., \& Maisto, S.A. (2007). Which heavy drinking college students benefit from a brief motivational intervention? Journal of Consulting and Clinical Psychology, 75, 663-669.

Carter, A.S., Pollock, R.A., Suvak, M.K., \& Pauls, D.L. (2004). Anxiety and major depression comorbidity in a family study of obsessive-compulsive disorder. Depression and Anxiety, 20, 165-174.

Chambless, D.L., Baker, M.J., Baucom, D.H., Beutler, L.E., Calhoun, K.S. et al. (1998). Update on empirically validated therapies, II. The Clinical Psychologist, 51, 316. 
Chambless, D.L. \& Hollon, S.D. (1998). Defining empirically supported therapist. Journal of Consulting and Clinical Psychology, 66, 7-18.

Chambless, D.L., Sanderson, W.C., Shoham, V., Johnson, S.B., Pope, K.S., CritsChristoph, P. et al. (1996). The Clinical Psychologist, 49, 5-18.

Chorpita, B.F., Taylor, A.A., Francis, S.E., Moffitt, C., Austin, A.A. (2004). Efficacy of modular cognitive behavior therapy of childhood anxiety disorders. Behavior Therapy, 35, 263-287.

Conger, A.J. (1974). A revised definition for suppressor variables: A guide to their identification and interpretation. Educational Psychological Measurement, 34, $35-46$.

Cooper, M. (1996). Obsessive compulsive disorder: Effects on family members. American Journal of Orthopsychiatry, 66, 296-304.

Cunningham, C.E., Benness, B.B., \& Siegel, L.S. (1988). Family functioning, time allocation, and parental depression in the families of normal and ADHD children. Journal of Clinical Child Psychology, 17, 160-177.

Davis, M. (1980). A multidimensional approach to individual differences in empathy. JSAS Catalog of Selected Documents in Psychology, 10, 85.

Davis, M.H. (1983). Measuring individual differences in empathy: Evidence for a multidimensional approach. Journal of Personality and Social Psychology, 44, 113-126.

Derogatis, L.R. (1993). The Brief Symptom Inventory (BSI): Administration, scoring and procedures manual (3rd ed.). Minneapolis, MN: National Computer Systems. 
Derogatis, L.R. \& Melisaratos, N. (1983). The Brief Symptom Inventory: An introductory report. Psychological Medicine, 13, 595-605.

de Haan, E. (2006). Effective treatment of OCD? Journal of the American Academy of Child and Adolescent Psychiatry, 45, 383.

Douglass, H.M., Moffitt, T.E., Dar, R., McGee, R., \& Silva, P. (1995). Obsessivecompulsive disorder in a birth cohort of 18-year-olds: Prevalence and predictors. Journal of the American Academy of Child and Adolescent Psychiatry, 34, 14241431.

Farrell, L.J. \& Barrett, P.M. (2007). The function of the family in childhood obsessivecompulsive disorder: Family interactions and accommodation. In E.A. Storch, G.R. Geffken, \& T.K. Murphy (Eds.), Handbook of Child and Adolescent Obsessive-Compulsive Disorder (pp. 313-332). Mahwah, NJ: Lawrence Erlbaum Associates.

Ferrao, Y.A., Shavitt, R.G., Bedin, N.R., deMathis, M.E., Lopes, A.C., Fontenelle, L.F. et al. (2006). Clinical features associated to refractory obsessive-compulsive disorder. Journal of Affective Disorders, 94, 199-209.

Foa, E.B. \& Kozak, M.J. (1986). Emotional processing of fear: Exposure to correct information. Psychological Bulletin, 99, 20-35.

Geffken, G.R., Storch, E.A., Duke, D.C., Monaco, D., Lewin A.D., \& Goodman, W.K. (2006). Hope and coping in family members of patient with obsessivecompulsive disorder. Anxiety Disorders, 20, 614-629. 
Geffken, G., Storch, E.A., Lewin, A., Adkins, J., Merlo, L., \& Murphy, T. (2005). Egosyntonic OCD: Preliminary data on the OCD Disturbance Scale. Paper presented at the annual meeting of the Anxiety Disorders Association of America. Seattle, Washington.

Geller, D.A., Biederman, J., Faraone, S., Agranat, A., Cradock, K., Hagermoser, L. et al. (2001). Developmental aspects of obsessive-compulsive disorder: Findings in children, adolescents, and adults. Journal of Nervous and Mental Disease, 189, 471-477.

Geller, D.A., Biederman, J., Griffin, S., Jones, J., \& Lefkowitz, T. (1996). Comorbidity of juvenile obsessive-compulsive disorder with disruptive behavior disorders. Journal of the American Academy of Child and Adolescent Psychiatry, 35, 16371646.

Ginsburg, G.S., Newman Kingery, J., Drake, K.L, \& Grados, M.A. (2008). Predictors of treatment response in pediatric obsessive-compulsive disorder. Journal of the American Academy of Child and Adolescent Psychiatry, 47, 868-878.

Goodman, W.K., Price, L.H., Rasmussen, S.A., Mazure, C., Fleischman, R.L., Hill, C.L. et al. (1989). The Yale-Brown Obsessive Compulsive Scale: I. Development, use, and reliability. Archives of General Psychiatry, 46, 1006-1011.

Goubert, L., Craig, K.D., Vervoot, T., Morley, S., Sullivan, A.C., de Williams, C. et al. (2005). Facing others in pain: The effects of empathy. Pain, 118, 285-288.

Hanna, G.L. (1995). Demographic and clinical features of obsessive-compulsive disorder in children and adolescents. Journal of the American Academy of Child and Adolescent Psychiatry, 34, 19-27. 
Haslam, D.M., Pakenham, K.I., \& Smith, A. (2006). Social support and postpartum depressive symptomatology: The mediating role of maternal self-efficacy. Infant Mental Health Journal, 27, 276-291.

Hathaway, S.R. \& McKinley, J.C. (1940). A multiphasic personality schedule (Minnesota): I. Construction of the Schedule. Journal of Psychology, 10, 249254.

Hoffman, M.L. (2000). Empathy and moral development: Implications for caring and justice. New York, NY: Cambridge University Press.

Hu, L.T. \& Bentler, P.M. (1999). Cutoff criteria for fit indices in covariance structure analysis: Conventional criteria versus new alternatives. Structural Equation Modeling, 6, 1-55.

Hudson, J.I., Mangweth, B., Pope, H.G., de Col, C., Hausmann, A., Gutweniger, S. et al. (2003). Family study of affective spectrum disorder. Archives of General Psychiatry, 60, 170-177.

Ivarsson, T., Melin, K., \& Wallin, L. (2008). Categorical and dimensional aspects of comorbidity in obsessive-compulsive disorder (OCD). European Child and Adolescent Psychiatry, 70, 20-31.

Joireman, J.A. (1999). Additional evidence for validity of the Consideration of Future Consequences Scale in an academic setting. Psychological Reports, 84, 11711172. 
Joireman, J., Anderson, J., \& Strathman, A. (2003). The aggression paradox: Understanding the links among aggression, sensation seeking, and the consideration of future consequences. Journal of Personality and Social Psychology, 84, 1287-1302.

Jöreskog, K.G. \& Sörbom, D. (2006). LISREL 8.80 for Windows [Computer software]. Lincolnwood, IL: Scientific Software International, Inc.

Kaufman, J., Birmaher, B., Brent, D.A., Rao, U., \& Ryan, N.D. (1997). Schedule for Affective Disorders and Schizophrenia for School Age Children, Present and Lifetime Version (K-SADS-PL): Initial reliability and validity data. Journal of the American Academy of Child and Adolescent Psychiatry, 36, 980-988.

Kazdin, A.E. (2005). Parent management training: Treatment for oppositional, aggressive, and antisocial behavior in children and adolescents. New York, NY: Oxford University Press.

Keeley, M.L., Storch, E.A., Merlo, L.J., \& Geffken, G.R. (2008). Clinical predictors of response to cognitive-behavioral therapy for obsessive-compulsive disorder. Clinical Psychology Review, 28, 118-130.

Kenny, D. \& Judd, C.M. (1984). Estimating the nonlinear and interactive effects of latent variables. Psychological Bulletin, 96, 201-210.

King, N.J., Ollendick, T.H., \& Montgomery, I.M. (1995). Obsessive-compulsive disorder in children and adolescents. Behavior Change, 12, 51-58.

Kline, R.B. (2005). Principles and practice of structural equation modeling ( $2^{\text {nd }}$ ed.). New York, NY: Guildford Press. 
Lindsey, J.J. \& Strathman, A. (1997). Predictors of recycling behavior: An application of a modified health belief model. Journal of Applied Social Psychology, 27, 1799-1823.

Linehan, M.M. (1993). Cognitive-behavioral treatment of borderline personality disorder. New York, NY: Guilford Press.

Lovejoy, M.C., Graczyk, P.A., O’Hare, E., \& Neuman, G. (2000). Maternal depression and parenting behavior: A meta-analytic review. Clinical Psychology Review, $20,561-592$.

Lyneham, H.J., Abbott, M.J., \& Rapee, R.M. (2007). Interrater reliability of the Anxiety Disorders Interview Schedule for DSM-IV: Child and parent version. Journal of the American Academy of Child and Adolescent Psychiatry, 46, 731-736.

MacKinnon, D.P., Krull, J.L., \& Lockwood, C.M. (2000). Equivalence of the mediation, confounding, and suppression effect. Prevention Science, 1, 173-181.

March, J., Frances, A., Carpenter, D., \& Kahn, D. (1997). Expert consensus guidelines: Treatment of obsessive-compulsive disorder. Journal of Clinical Psychology, 58, $1-72$.

March, J.S., Franklin, M., Nelson, A. \& Foa, E. (2001). Cognitive-behavioral psychotherapy for pediatric obsessive-compulsive disorder. Journal of Clinical Child Psychology, 30, 8-18.

March, J., Parker, J., Sullivan, K., Stallings, P., \& Conners, K. (1997). The Multidimensional Anxiety Scale for Children: Factor structure, reliability, and validity. Journal of the American Academy, 36, 554-565. 
Mardia, K.V. (1970). Measures of multivariate skewness and kurtosis with applications. Biometrika, 57(3), 519-530.

Mardia, K.V. (1985). Mardia's test of multivariate normality. In S. Kotz \& N.L. Johnson (Eds.), Encyclopedia of statistical sciences (Vol. 5, pp. 217-22). New York, NY: Wiley.

Masi, G., Mucci, M., Nicolette, B., Bertini, N., Milatoni, L. \& Arcangeli, F. (2005). A naturalistic study of referred children and adolescents with obsessive-compulsive disorder. Journal of the American Academy of Child and Adolescent Psychiatry, $44,673-681$.

Matais-Cols, D., Frost, R.O., Pertusa, A., Clark, L.A., Saxena, S., Leckman, J.F., et al. (2010). Hoarding Disorder: A new diagnosis for DSM-V? Depression and Anxiety, 0, 1-17.

Mataix-Cols, D., Nakatani, E., Micali, N., \& Heyman, I. (2008). Structure of obsessivecompulsive symptoms in pediatric OCD. Journal of the American Academy of Child and Adolescent Psychiatry, 47, 773-778.

McGoldrick, M., Giordano, J., \& Garcia-Preto, N. (Eds.). (2005). Ethnicity and family therapy ( $3^{\text {rd }}$ ed.). New York, NY: Guilford Press.

McKay, D., Abramowitz, J.S., Calamari, J.E., Kyrios, M., Radomsky, A.S., Sookman, D. et al. (2004). A critical evaluation of obsessive-compulsive disorder subtypes: Symptoms versus mechanisms. Clinical Psychology Review, 24, 283-313. 
Merlo, L.J., Lehmkuhl, H.D., Geffken, G.R., \& Storch, E.A. (2009). Decreased family accommodation associated with improved therapy outcome in pediatric obsessivecompulsive disorder. Journal of Consulting and Clinical Psychology, 77, 355360.

Merlo, L.J. Storch. E.A., Lehmkuhl, H.D., Jacob, M.L., Murphy, T.K., Goodman, W.K., et al. (2010). Cognitive behavioral therapy plus motivational interviewing improves outcome for pediatric obsessive-compulsive disorder: A preliminary study. Cognitive Behaviour Therapy, 39, 24-27.

Merlo, L.J., Storch, E.A., Murphy, T.K., Goodman, W.K., \& Geffken, G.R. (2005). Assessment of pediatric obsessive-compulsive disorder: A critical review of current methodology. Child Psychiatry and Human Development, 36, 195-214.

Miller, P.A. \& Eisenberg, N. (1988). The relation of empathy to aggressive and externalizing/antisocial behavior. Psychological Bulletin, 103, 324-344.

Nestadt, G., Samuels, J., Riddle, M.A., Liang, K.Y., Bienvenu, O.J., Hoehn-Saric, R. et al. (2001). The relationship between obsessive-compulsive disorder and anxiety and affective disorders: Results from the John Hopkins OCD Family Study. Psychological Medicine, 31, 481-487.

Obsessive-Compulsive Cognitions Working Group (2003). Psychometric validation of the Obsessive Beliefs Questionnaire and the Interpretation of Intrusions Inventory: Part I. Behaviour Research and Therapy, 41, 863-878.

Orbell, S. \& Kyriakaki, M. (2008). Temporal framing and persuasion to adopt preventive health behavior: Moderating effects of individual differences in consideration of future consequences on sunscreen use. Health Psychology, 27, 770-779. 
Pediatric OCD Study Team (2004). Cognitive-behavior therapy, sertraline, and their combination for children and adolescents with obsessive-compulsive disorder: The pediatric OCD Treatment Study randomized controlled trial. Journal of the American Medical Association, 292, 1969-1976.

Peris, T.S., Bergman, L., Langley, A., Chang, S., McCracken, J.T., \& Piacentini, J. (2008). Correlates of accommodation of pediatric obsessive-compulsive disorder: Parent, child, and family characteristics. Journal of the American Academy of Child and Adolescent Psychiatry, 47, 1-9.

Peterson, B.S., Pine, D.S., Cohen, P., \& Brook, J.S. (2001). Prospective, longitudinal study of tic, obsessive-compulsive, and attention-deficit/hyperactivity disorders in an epidemiological sample. Journal of the American Academy of Child and Adolescent Psychiatry, 40, 685-695.

Piacentini, J., Bergman, R.L., Jacobs, C., McCracken, J.T., \& Kretchman, J. (2002). Open trial of cognitive behavior therapy for childhood obsessive-compulsive disorder. Journal of Anxiety Disorders, 16, 207-219.

Piacentini, J., Bergman, R.L., Keller, M., \& McCracken, J. (2003). Functional impairment in children and adolescent with obsessive-compulsive disorder. Journal of Child and Adolescent Psychopharmacology, 13, S61-S69.

Piacentini, J. \& Jaffer, M. (1999). Measuring functional impairment in youngsters with OCD (Manual for the Child Obsessive-Compulsive Impact Scale, COIS). Los Angeles, CA: UCLA Department of Psychiatry. 
Piacentini, J., Peris, T.S., Bergman, R.L., Chang, S., \& Jaffer, M. (2007). Functional impairment in childhood OCD: Development and psychometric properties of the Child Obsessive Compulsive Impact Scale_-Revised. Journal of Clinical Child and Adolescent Psychology, 36, 645-653.

Ping, R.A. (1996). Latent variable interaction and quadratic effect estimation: A twostep technique using structural equation analysis. Psychological Bulletin, 119, 166-175.

Preston, S.D. \& deWaal, F.B.M. (2002). Empathy: Its ultimate and proximate bases. Behavioral and Brain Sciences, 25, 1-72.

Rachman, S. (1997). A cognitive theory of obsessions. Behaviour Research and Therapy, 36, 793-802.

Rachman, S. (1998). A cognitive theory of obsessions: elaborations. Behaviour Research and Therapy, 36, 395-401.

Rapoport, J.L., Inoff-Germain, G., Weissman, M.M., Greenwald, S., Narrow, W.E., Jensen, P.S. et al. (2000). Childhood obsessive-compulsive disorder in the NIMH MECA Study: Parent versus child identification of cases. Journal of Anxiety Disorders, 14, 535-548.

Renshaw, K.D., Steketee, G., \& Chambless, D.L. (2005). Involving family members in the treatment of OCD. Cognitive Behaviour Therapy, 34, 164-175.

Rettew, D.C., Swedo, S.E., Leonard, H.L., Lenane, M.C., \& Rapoport, J.L (1992). Obsessions and compulsions across time in 79 children and adolescents with obsessive-compulsive disorder. Journal of the American Academy of Child and Adolescent Psychiatry, 31, 1050-1056. 
Reynolds, W.M. (Ed.), (1992). Internalizing disorders in children and adolescents. New York, NY: Wiley.

Reynolds, S. \& Reeves, J. (2008). Do cognitive models of obsessive compulsive disorder apply to children and adolescents? Behavioural and Cognitive Psychotherapy, $36,463-471$.

Riddle, M.A., Scahill, L., King, R., Hardin, M.T., Towbin, K.E., Ort, S.I. et al. (1990). Obsessive-compulsive disorder in children and adolescents: Phenomenology and family history. Journal of the American Academy of Child and Adolescent Psychiatry, 29(5), 766-772.

Rufer, M., Grothusen, A., Mass, R., Peter, J., \& Hand, I. (2005). Temporal stability of symptom dimensions in adult patients with obsessive-compulsive disorder. Journal of Affective Disorders, 88, 99-102.

Salkovskis, P.M. (1985). Obsessional-compulsive problems: A cognitive behavioural analysis. Behaviour Research and Therapy, 23, 571-583.

Salkovskis, P.M. (1989). Obsessions and compulsions. In J. Scott, J.M. Williams, \& A.T. Beck (Eds.), Cognitive therapy in clinical practice: An illustrative casebook (pp. 50-77). Florence, KY: Taylor \& Francis/Routledge.

Scahill, L., Riddle, M.A., McSwiggin-Hardin, M., Ort, S.I., King, R.A., Goodman, W.K. (1997). Children's Yale-Brown Obsessive-Compulsive Scale: Reliability and validity. Journal of the American Academy of Child and Adolescent Psychiatry, $36,844-852$.

Seligman, M.E.P. (1975). Helplessness: On depression, development and death. New York, NY: W.H. Freeman and Company. 
Shafran, R., Ralph, J., \& Tallis, F. (1995). Obsessive-compulsive symptoms and the family. Bulletin of the Menninger Clinic, 59(4), 472-479.

Silverman, W. \& Albano, A. (1996). The Anxiety Disorders Interview Schedule for DSM-IV: Child and Parent Version. San Antonio, TX: Graywind.

Silverman, W.K., Saavedra, L.M., \& Pina, A.A. (2001). Test-retest reliability of anxiety symptoms and diagnoses with Anxiety Disorders Interview Schedule for DSMIV: Child and parent versions. Journal of the American Academy of Child and Adolescent Psychiatry, 40, 937-943.

Sobel, M.E. (1982). Asymptotic confidence intervals for indirect effects in structural equation models. Sociological Methodology, 13, 290-312.

Spielberger, C.D., Gorsuch, R.L., Lushene, R.E., \& Jacobs, G.A. (1983). Manual for the State-Trait Anxiety Inventory (STAI). Palo Alto, CA: Consulting Psychologists Press.

Steiger, J.H. (1990). Structural model evaluation and modification: An interval estimation approach. Multivariate Behavioral Research, 25, 173-180.

Steketee, G. (1993). Social support and treatment outcome of obsessive-compulsive disorder at 9-month follow-up. Behavioral Psychotherapy, 21, 81-95.

Steketee, G. \& Van Noppen, B. (2003). Family approaches to treatment for obsessivecompulsive disorder. Revista Brasileira de Psuiquiatria, 25, 43-50.

Stewart, S.E., Beresin, C., Haddad, S., Egan Stack, D., Fama, J., \& Jenike, M. (2008a). Predictors of family accommodation in obsessive-compulsive disorder. Annals of Clinical Psychiatry, 20, 65-70. 
Stewart, S.E., Rosario, M.C., Baer, L., Carter, A.S., Brown, T.A., Scharft, J.M. et al. (2008b). Four-factor structure of obsessive-compulsive disorder symptoms in children, adolescents, and adults. Journal of the American Academy of Child and Adolescent Psychiatry, 47, 763-772.

Stewart, S.E., Rosario, M.C., Brown, T.A., Carter, A.S., Leckman, J.F., Dukhodolsky, D. et al. (2007). Principal components analysis of obsessive-compulsive disorder symptoms in children and adolescents. Journal of Biological Psychiatry, 61, 285291.

Storch, E.A., Abramowitz, J., \& Goodman, W.K. (2008). Where does obsessivecompulsive disorder belong in the DSM-V? Depression and Anxiety, 25, 336347.

Storch, E.A., Geffken, G.R., Adkins, J.W., Murphy, T.K., \& Goodman, W.K. (2007). Intensive cognitive-behavioral psychotherapy for treatment-resistant pediatric obsessive-compulsive disorder: A case series of five patients. Depression and Anxiety, 24, 375-381.

Storch, E.A., Geffken, G.R., Merlo, L.J., Jacob, M.L., Murphy, T.K., Goodman, W.K. et al. (2007a). Family accommodation in pediatric obsessive-compulsive disorder. Journal of Clinical Child and Adolescent Psychology, 36, 207-216.

Storch, E.A., Geffken, G.R., Merlo, L.J., Mann, G., Duke, D., Munson, M. et al. (2007b). Family-based cognitive-behavioral therapy for pediatric obsessive-compulsive disorder: Comparison of intensive and weekly approaches. Journal of the American Academy of Child and Adolescent Psychiatry, 46, 469-478. 
Storch, E.A., Lack, C.W., Merlo, L.J., Geffken, G.R., Jacob, M.L., Murphy, T.K. et al. (2007c). Clinical features of children and adolescents with obsessive-compulsive disorder and hoarding symptoms. Comprehensive Psychiatry, 48, 313-318.

Storch, E.A., Larson, M.J., Merlo, L.J., Keeley, M.L., Jacob, M.L., Geffken, G.R., Murphy, T.K. et al. (2008a). Comorbidity of pediatric obsessive-compulsive disorder and anxiety disorders: Impact on symptom severity and impairment. Journal of Psychopathology and Behavioral Assessment, 30, 111-120.

Storch, E.A., Larson, M.J., Muroff, J., Caporino, N., Geller, D., Reid, J.M., et al. (2010). Predictors of functional impairment in pediatric obsessive-compulsive disorder. Journal of Anxiety Disorders, 24, 275-283.

Storch, E.A., Merlo, L.J., Larson, M., Geffken, G.R., Lehmkuhl, H.D., Jacob, M.L. et al. (2008b). Impact of comorbidity on cognitive-behavioral therapy response in pediatric obsessive-compulsive disorder. Journal of the American Academy of Child and Adolescent Psychiatry, 47, 583-592.

Storch, E.A., Merlo, L.J., Larson, M.J., Marien, W.E., Geffken, G.R., Jacob, M.L. et al. (2008). Clinical features associated with treatment-resistant pediatric obsessivecompulsive disorder. Comprehensive Psychiatry, 49, 35-42.

Storch, E.A., Murphy, T.K., Geffken, G.R., Soto, O., Sajid, M., Allen, P. et al. (2004). Psychometric evaluation of the Children's Yale-Brown Obsessive-Compulsive Scale. Psychiatry Research, 129, 91-98.

Strathman, A., Gleicher, F., Boninger, D.S., \& Edwards, C.S. (1994). The consideration of future consequences: Weighing immediate and distant outcomes of behavior. Journal of Personality and Social Psychology, 66, 742-752. 
Swedo, S.E., Rapoport, J.L., Leonard, H.L., Lenane, M., \& Cheslow, D. (1989). Obsessive-compulsive disorder in children and adolescents: Clinical phenomenology of 70 consecutive cases. Archives of General Psychiatry, 46, $335-341$.

Teti, D.M. \& Gelfand, D.M. (1991). Behavioral competence among mothers of infants in the first years: The mediation role of maternal self-efficacy. Child Development, 72, 918-929.

Valderhaug, R. \& Ivarsson, T. (2005). Functional impairment in clinical samples of Norwegian and Swedish children and adolescents with obsessive-compulsive disorder. European Child and Adolescent Psychiatry, 14, 164-173.

Waters, T.L. \& Barrett, P.M. (2000). The role of the family in childhood obsessivecompulsive disorder. Clinical Child and Family Psychology Review, 3, 173-184.

Wood, J., Piacentini, J., Bergman, R.L., McCracken, J., \& Barrios, V. (2002).

Concurrent validity of the anxiety disorders section of the Anxiety Disorders Interview Schedule for DSM-IV: Child and parent versions. Journal of Clinical Child and Adolescent Psychology, 31, 335-342.

Zimbardo, P.G. \& Boyd, J.N. (1999). Putting time in perspective: A valid, reliable individual differences metric. Journal of Personality and Social Psychology, 77, $1271-1288$.

Zohar, A.H. (1999). The epidemiology of obsessive-compulsive disorder in children and adolescence. Child and Adolescent Psychiatric Clinics of North America, 8, 445460. 